\title{
Ventilation in patients with intra-abdominal hypertension: what every critical care physician needs to know
}

\author{
Adrian Regli ${ }^{1,2,3}$, Paolo Pelosi ${ }^{4,5}$ and Manu L. N. G. Malbrain ${ }^{6,7^{*}}$ (i)
}

\begin{abstract}
The incidence of intra-abdominal hypertension (IAH) is high and still underappreciated by critical care physicians throughout the world. One in four to one in three patients will have IAH on admission, while one out of two will develop IAH within the first week of Intensive Care Unit stay. IAH is associated with high morbidity and mortality. Although considerable progress has been made over the past decades, some important questions remain regarding the optimal ventilation management in patients with IAH. An important first step is to measure intra-abdominal pressure (IAP). If IAH (IAP> $12 \mathrm{mmHg}$ ) is present, medical therapies should be initiated to reduce IAP as small reductions in intra-abdominal volume can significantly reduce IAP and airway pressures. Protective lung ventilation with low tidal volumes in patients with respiratory failure and IAH is important. Abdominal-thoracic pressure transmission is around 50\%. In patients with IAH, higher positive end-expiratory pressure (PEEP) levels are often required to avoid alveolar collapse but the optimal PEEP in these patients is still unknown. During recruitment manoeuvres, higher opening pressures may be required while closely monitoring oxygenation and the haemodynamic response. During lung-protective ventilation, whilst keeping driving pressures within safe limits, higher plateau pressures than normally considered might be acceptable. Monitoring of the respiratory function and adapting the ventilatory settings during anaesthesia and critical care are of great importance. This review will focus on how to deal with the respiratory derangements in critically ill patients with IAH.
\end{abstract}

Keywords: Intra-abdominal pressure, Intra-abdominal hypertension, Abdominal compartment syndrome, Mechanical ventilation, Recruitment, Compliance, Positive end-expiratory pressure, Ventilator-induced lung injury, Protective ventilation, Driving pressure

\section{Background}

Intra-abdominal hypertension (IAH) is defined as a sustained increase in intra-abdominal pressure (IAP) equal to or above $12 \mathrm{mmHg}$ [1]. Critical care physicians around the world still underestimate the high incidence of IAH which is around $25 \%$ in mixed ICU patients $[2,3]$.

IAH is associated with increased morbidity and mortality $[2,4]$ and is mainly caused by too much intraabdominal volume within the abdominal cavity $[5,6]$.

*Correspondence: manu.malbrain@uzbrussel.be

${ }^{6}$ Intensive Care Unit, University Hospital Brussels (UZB), Jette, Belgium

Full list of author information is available at the end of the article
IAH directly impacts on organ function of the abdominal organs such as kidney and liver. Furthermore, IAH can affect the function of organs outside the abdominal cavity including the brain, the cardiovascular system and the lungs [7]. Figure 1 summarizes the pathophysiologic effect of IAH on end-organ function.

IAH affects mainly respiratory mechanics and only in part oxygenation. IAH causes a cephalad shift of the diaphragm thereby increasing intra-thoracic pressures and reducing chest wall compliance and lung volumes [8]. Table 1 lists other factors that affect "chest wall" compliance.

The aim of this review is to discuss the effects of $\mathrm{IAH}$ on respiratory function and the ventilatory 


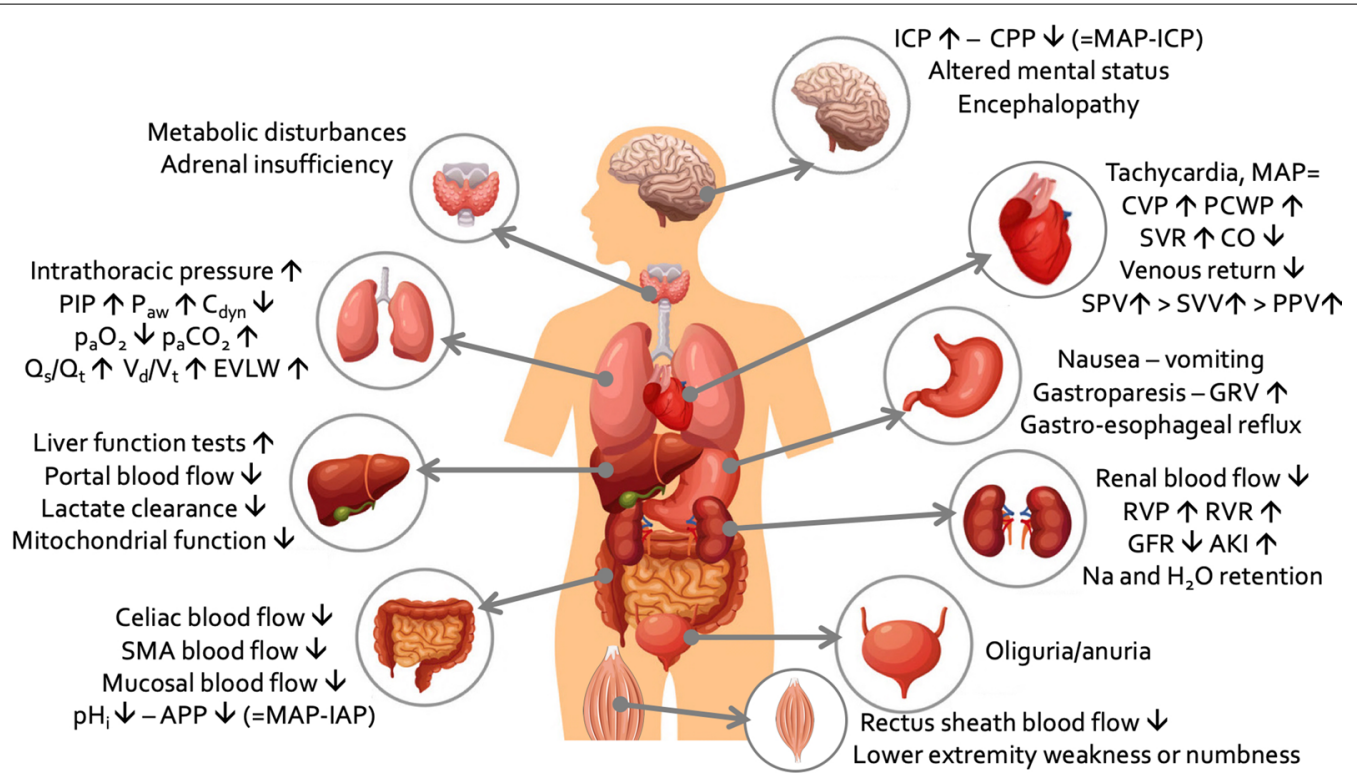

Fig. 1 Summary of the most important pathophysiologic effects of increased intra-abdominal pressure on end-organ function within and outside the abdominal cavity. AKI acute kidney injury, APP abdominal perfusion pressure, Cdyn dynamic respiratory compliance, CO cardiac output, CPP cerebral perfusion pressure, CVP central venous pressure, EVLW extravascular lung water, GFR glomerular filtration rate, GRV gastric residual volume, $H R$ heart rate, IAP intra-abdominal pressure, ICP intra-cranial pressure, ITP intra-thoracic pressure, MAP mean arterial pressure, PIP peak inspiratory pressure, Paw airway pressures, $P C W P$ pulmonary capillary wedge pressure, $p H i$ intra-mucosal gastric $\mathrm{pH}, P P V$ pulse pressure variation, Qs/Qt shunt fraction, RVP renal venous pressure, RVR renal vascular resistance, SMA superior mesenteric artery, SPV systolic pressure variation, SVR systemic vascular resistance, SW stroke volume variation, VdNt dead-space ventilation. Adapted from Malbrain et al. with permission [126]

\section{Table 1 Factors that affect "chest wall" compliance}

Direct effect on chest wall
Pleural effusion
Lung transplant
Sternotomy (post-CABG)
Obesity
Fluid overload
Rib fractures
Indirect effect on chest wall_-intra-abdominal hypertension (IAH)
Abdominal distension
Ascites
Fluid overload
Obesity

management of patients with IAH, needless to state that the ventilatory management of patients with IAH has to take into account not only the respiratory effects of IAH but also the consequences of any underlying chronic lung disease or a newly acquired lung injury.

\section{Epidemiology}

\section{Intra-abdominal hypertension}

Around one in four to one in three patients present with IAH on admission to intensive care unit (ICU) while around one in two will develop IAH within the first week of ICU stay $[2,9]$. Moreover, one in twenty mixed ICU patients will develop overt abdominal compartment syndrome, a lethal syndrome with a mortality rate above $75 \%$ when left untreated [4]. To this day, patients may have unrecognized IAH as awareness is still low [3]. The risk factors for IAH include abdominal surgery, surgery performed in the emergency setting, severe poly-trauma, abdominal trauma, severe haemorrhagic shock, severe burns, severe acute pancreatitis, large volume fluid resuscitation (especially crystalloid) resulting in fluid overload, ileus, and liver dysfunction [10].

\section{Respiratory failure and intra-abdominal hypertension}

Patients receiving mechanical ventilation are more likely to have IAH $[11,12]$. Also, patients with respiratory failure $\mathrm{PaO}_{2} / \mathrm{F}_{\mathrm{i}} \mathrm{O}_{2}$ ratio $<300 \mathrm{mmHg}$, or receiving positive end-expiratory pressure (PEEP) $>10 \mathrm{cmH}_{2} \mathrm{O}$ or having a peak airway pressure $>28 \mathrm{cmH}_{2} \mathrm{O}$ are more likely to have IAH $[12,13]$. Others did not find an association between mechanical ventilation and IAH [14]. Table 2 lists the respiratory effects induced by IAH. 
Table 2 Respiratory effects related to increased IAP

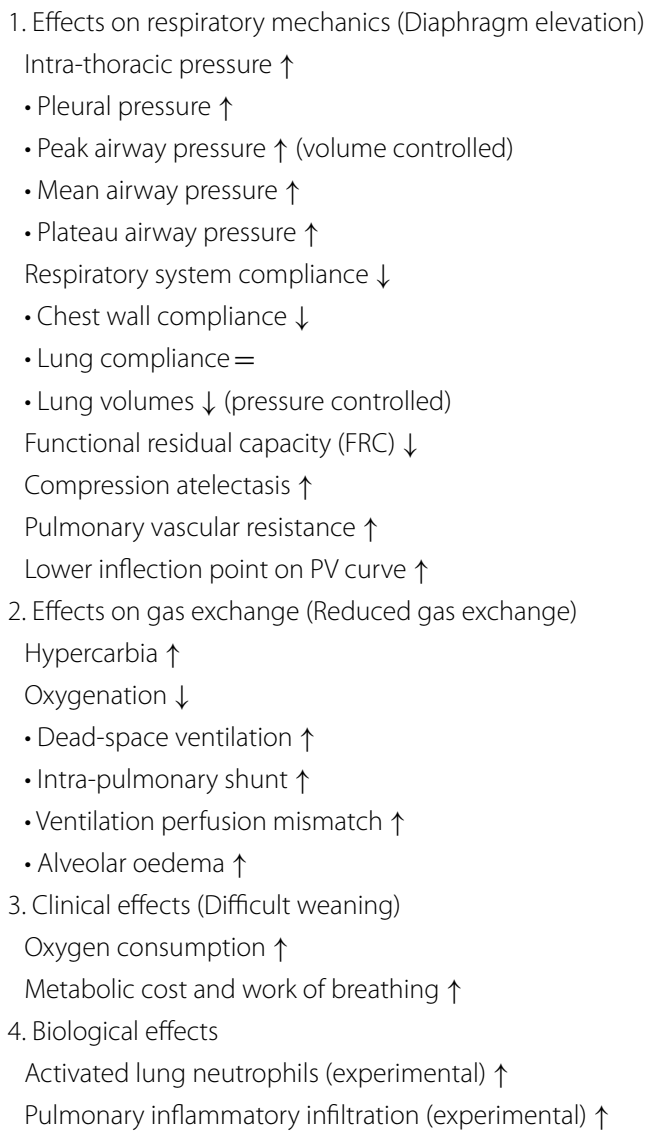

\section{Key message 1: Epidemiology and IAH}

The average incidence of IAH in critically ill patients is around $25-30 \%$ on admission, and the cumulative incidence is around $50 \%$ during the first week of ICU stay. There is an association between patients having IAH and respiratory failure.

\section{Effects of intra-abdominal hypertension on respiratory function}

Effect of intra-abdominal hypertension on lung volumes Pathophysiology

IAH causes a cranial shift of the diaphragm, thereby increasing intra-thoracic pressures affecting lung volumes and respiratory mechanics [8]. IAH is associated with reduced lung volumes as shown in many animal experiments [15-19]. Lung volumes decline with increasing degree of IAH $[18,19]$.

\section{Animal data}

In pigs, increasing IAP from baseline to 12, 18 and $22 \mathrm{mmHg}$ decreased end-expiratory lung volumes by 30 , 46 and $49 \%$ respectively [19]. There are insufficient data to know at what level of IAP lung volumes reduce or atelectasis occurs. At least in pigs, lung volumes decline with increasing degree of IAH [18, 19]. For example, Mutoh et al. [20] inflated in piglet an abdominal balloon in small increments and found that end-expiratory lung volumes reduced even after small increases of IAP. Quintel et al. [15] applied in pigs an IAP of $15 \mathrm{mmHg}$ and measured thoracic lung volumes using computer tomography. IAH increased the percentage of atelectatic as well as poorly aerated lungs.

\section{Human data}

In another study including 16 patients undergoing decompressive laparotomy, different lung volumes were calculated with computed tomography at baseline, before and after decompressive laparotomy [21]. IAP increased from $12 \mathrm{mmHg}$ at baseline to $25 \mathrm{mmHg}$ prior to laparotomy. Total lung volume decreased from 3.2 to $2.4 \mathrm{~L}$, and the percentage of atelectatic and poorly aerated lung increased. Following laparotomy, these lung changes partially reversed (Fig. 2). In these patients, laparotomy reduced IAP from 25 to $15 \mathrm{mmHg}$ and improved lung volumes from 2.4 to $2.9 \mathrm{~L}$ [21]. Not only was the diaphragm cranially displaced but the lungs also expanded their sagittal diameter in compensation [21].

\section{Key message 2: Effect of IAH on lung volumes}

The presence of IAH is associated with a decrease in lung volumes, while decompressive laparotomy results in an improvement in lung volumes.

\section{Effect of intra-abdominal hypertension on respiratory mechanics \\ Pathophysiology}

By using oesophageal catheter, the total respiratory system compliance $\left(C_{\mathrm{RS}}\right)$ can be compartmentalized and chest wall $\left(C_{\mathrm{CW}}\right)$ and lung compliance $\left(C_{\mathrm{L}}\right)$ are derived (see below). Table 1 summarizes the factors that might affect $C_{\mathrm{CW}}$ and can be broadly divided into direct influence and indirect influence of chest wall via IAH.

\section{Animal data}

In pigs with IAH and healthy lungs, respiratory compliance has been shown to decline mainly due to a reduction in $C_{C W}[15,19,22]$. With increasing IAP, both $C_{\mathrm{RS}}$ and $C_{\mathrm{CW}}$ compliances decrease significantly $[19,22]$. This decrease is more pronounced for the chest wall and shows a strong inverse correlation with IAP [22]. Previous studies in animal and human focusing on the importance of IAH showed that abdominal and subsequently chest wall compliance improves after abdominal decompression $[16,17]$. 


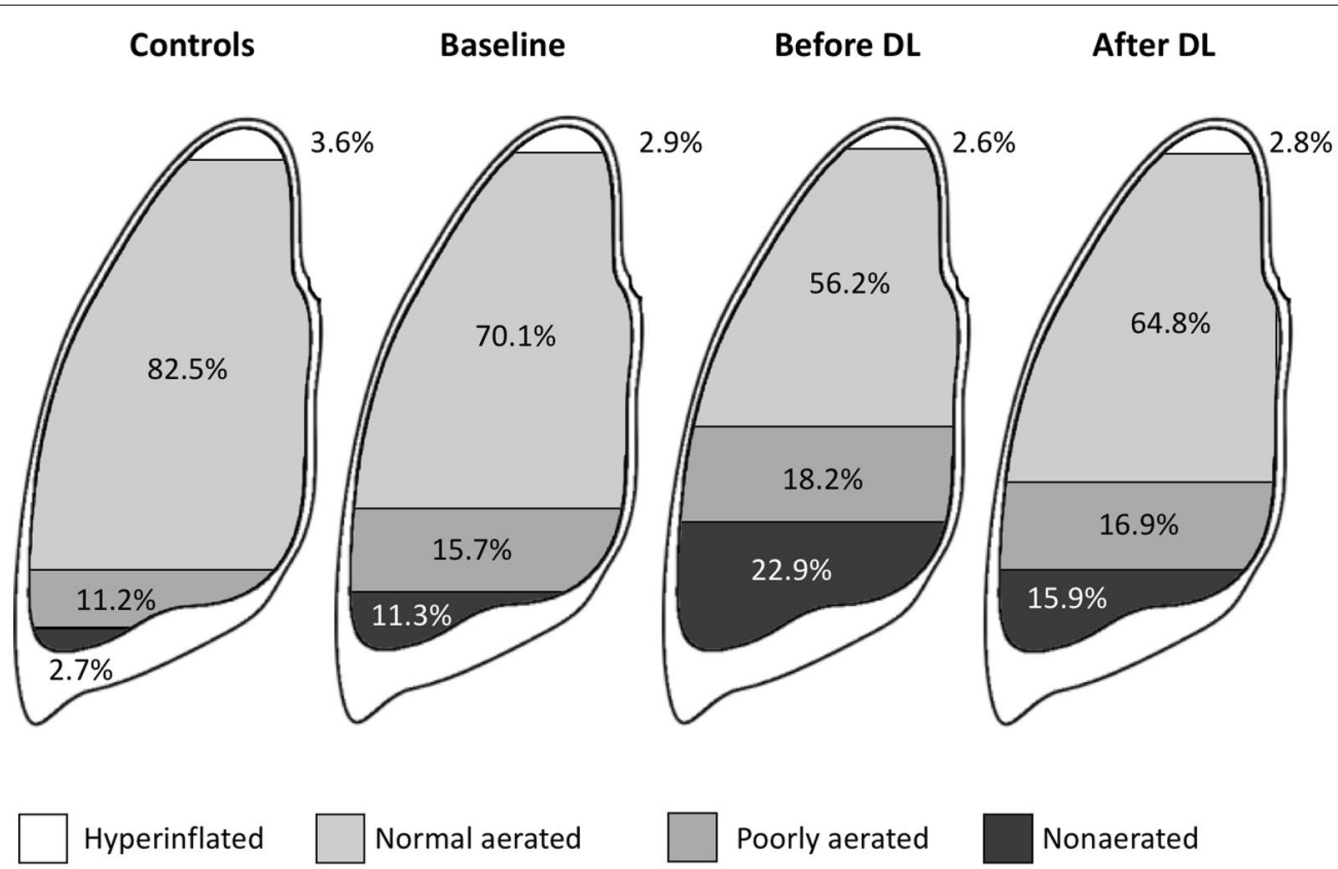

Fig. 2 Effect of abdominal hypertension and decompressive laparotomy (DL) on total lung volumes expressed percentages of different aerated lung volumes. Adapted from Zhou et al. [21]

\section{Human data}

In humans, IAH also appears to impair respiratory system compliance mainly through a reduction of chest wall compliance. Ranieri et al. [16] assessed respiratory mechanics in 18 patients with acute respiratory distress syndrome (ARDS). Half of these patients required major abdominal surgery. Before surgery, these patients had a smaller $C_{\mathrm{RS}}$ and $C_{\mathrm{CW}}$ in comparison to the patients that did not require abdominal surgery and their respiratory mechanics partially improved after decompressive laparotomy.

Gattinoni et al. [23] equally assessed respiratory mechanics in 9 patients with extrapulmonary ARDS and 12 patients with pulmonary ARDS. The patients with extrapulmonary ARDS had higher IAP levels and smaller $C_{\mathrm{CW}}$.

Despite IAH being a frequent cause of reduced chest wall compliance, it is still neglected by critical care physicians [5].

\section{Key message 3: Effect of IAH on respiratory mechanics}

The effects of IAH on respiratory function can be characterized by a decrease in chest wall compliance.

\section{Airway pressures and abdominal-thoracic transmission Pathophysiology}

IAH can increase intra-thoracic pressures and thereby affect airway pressures as well as pleural and central vascular pressures $[7,19,21]$. In this context, abdominal-thoracic transmission (ATT) describes the percentage increase in thoracic pressures for each incremental increase of IAP [22].

\section{Animal data}

In pigs, peak and plateau airway pressures increase proportionally with raising IAP $[24,25]$. ATT for plateau pressure has been found to be between 40 and 50\% [22, $26,27]$. ATT for peak airway pressure has been found to be between 38 and $62 \%[18,22]$. Similarly, oesophageal pressure is subject to ATT. Mainly inspiratory pleural pressure increase due to IAH with reported inspiratory pleural pressure of between 35 and 63\% [19, 22]. In a pig study $(n=11)$, IAH up to $30 \mathrm{mmHg}$ resulted in an ATT between 17 and 62\% when looking at end-expiratory and end-inspiratory oesophageal pressures respectively [22].

Increasing intra-abdominal volume increases IAP exponentially $[5,6,26,28]$. In a pig model of $\mathrm{IAH}$, increasing intra-abdominal volume has also been shown to increase peak airway pressures exponentially (Fig. 3) [26]. This exponential pressure-volume relationship is well-known from the Monroe-Kellie doctrine used in patients with intra-cranial hypertension. Similarly, in patients with IAH that already have a large amount of additional intra-abdominal volume, small changes in 


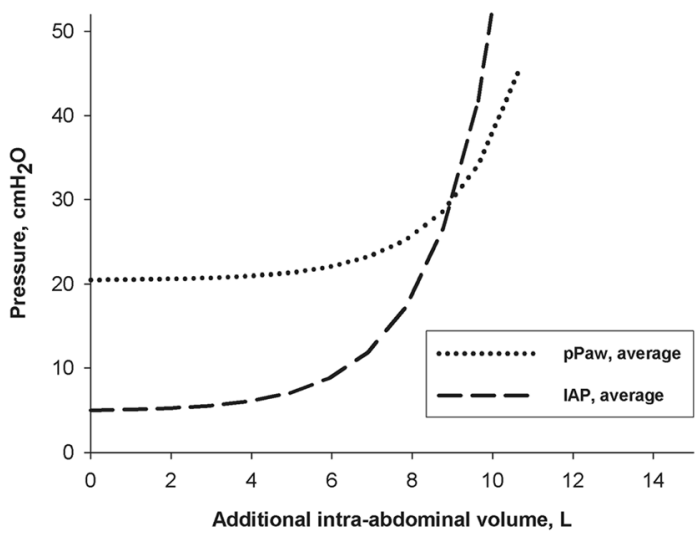

Fig. 3 Exponential pressure-volume curves of intra-abdominal pressure (IAP) (dashed curve) and peak airway pressure (pPAW) (dotted curve) in centimetre of water in function of increasing additional intra-abdominal volume in litres derived from 7 pigs. Figure reproduced with permission from Regli et al. [26]

intra-abdominal volume can significantly affect IAP and airway pressures $[5,6]$.

\section{Human data}

In humans, ATT for plateau pressure can be estimated to be $20 \%$. Torquato et al. [24] showed that placing $5 \mathrm{~kg}$ weights on the abdomen of mechanically ventilated critically ill patients increased IAP from 10.5 to $15.6 \mathrm{cmH}_{2} \mathrm{O}$ and plateau airway pressures from 22.4 to $23.6 \mathrm{cmH}_{2} \mathrm{O}$ ). In another study, ATT for peak airway pressure was around $62 \%$ [21].

A pilot study in 14 mechanically ventilated patients with ARDS showed that the application of an abdominal Velcro belt increased IAP from 8.6 to $15.4 \mathrm{mmHg}$ with a concomitant increase in alveolar plateau pressures from 18.0 to $23.3 \mathrm{cmH}_{2} \mathrm{O}$ (data on file). ATT for plateau pressure was therefore $57 \%$. These changes were paralleled by a decrease in dynamic $C_{\mathrm{RS}}$ from 37 to $28 \mathrm{~mL} / \mathrm{cmH}_{2} \mathrm{O}$. It might be important to note that the above studies were performed in the supine position yet we know that body position has a substantial influence on IAP and lung function [25].

\section{Effect of abdominal-thoracic transmission on trans-pulmonary pressures}

Trans-pulmonary pressures, the difference between airway and pleural pressures, and not the plateau pressures are thought to be responsible for causing ventilator-induced lung injury $[29,30]$. Because IAH increases inspiratory peak airway, plateau and pleural pressures similarly, the impact on trans-pulmonary pressures is only minimal. This explains why suggested lung-protective ventilation strategies with maintaining plateau pressures below $30 \mathrm{cmH}_{2} \mathrm{O}$ are difficult to apply in patients with IAH and diminished chest wall compliance.

\section{Key message 4: Effect and transmission of IAH on airway pressures}

In summary, in animals and humans, ATT of peak and plateau airway pressure have been reported to be between 20 and $60 \%$ [31]. In pigs, ATT of airway pressures and pleural pressures are similar. We suspect this to be the case also in humans. IAH has little influence on trans-pulmonary pressures as IAH increases both inspiratory airway and pleural pressures equally.

\section{Lung oedema and lymphatic drainage \\ Pathophysiology}

Fluid drainage from the lungs can take place via three mechanisms: trans-pleural, via the lung hilus or transabdominal [32].

\section{Animal data}

Mechanical ventilation with positive pressure per se as opposed to spontaneous ventilation decreases abdominal lymphatic drainage [33]. A landmark paper by Quintel et al. [15] showed that IAH causes an increase in lung oedema in a pig model of acute lung injury (induced by oleic acid). Increasing IAP from 0 to $20 \mathrm{cmH}_{2} \mathrm{O}$ changed lung oedema distribution from the dorsobasal regions to the complete lung. In line with these results, Schachtrupp et al. [34, 35] showed an increase in extravascular lung water (EVLW) and histological lung alterations at IAP levels of $30 \mathrm{cmH}_{2} \mathrm{O}$.

The effects of different ventilatory settings and increasing IAP on thoracic and abdominal lymph flow was studied in a porcine endotoxin sepsis model [36]. The study was performed in three parts, and data were collected from a total of 32 pigs. In summary, the authors found that lipopolysaccharide infusion increased IAP and abdominal (trans-diaphragmatic) lymphatic drainage, that PEEP increased IAP but impeded abdominal lymphatic drainage, that spontaneous breathing improved abdominal lymph drainage, and finally that IAH diminished abdominal lymphatic drainage [37].

\section{Human data}

A retrospective observational study of 123 mechanically ventilated patients found that the patients that achieved a negative fluid balance in their first week of ICU stay had 
lower EVLW, IAP, and C-reactive protein over albumin ratios as well as a higher 28-day survival rate [38]. This correlation between IAP, fluid balance and EVLW suggests a link between sepsis, capillary leak, fluid overload, IAH and lung oedema. This may explain why active fluid removal or so-called de-resuscitation with PAL-treatment (PEEP in $\mathrm{cmH}_{2} \mathrm{O}$ set at the level of IAP in $\mathrm{mmHg}$, followed by hyperoncotic albumin $20 \%$ and Lasix ${ }^{\circledR}$ ) was able to reduce cumulative fluid balance, IAP, EVLW and 28-day mortality in a retrospective matched case-control study of 57 patients with acute respiratory failure [39, 40]. Different pathologies and treatments can markedly influence the pathophysiology of the lymphatics with dramatic effects on end-organ function.

\section{Key message 5: Effect of IAH on lymphatic}

The presence of IAH affects lymphatic drainage between the thoracic and abdominal cavity and may play an important role in the development of oedema formation.

\section{Oxygenation and ventilation Pathophysiology}

In general, IAH results in a decreased oxygenation and an increase in hypercarbia caused by increased deadspace ventilation and shunt and ventilation perfusion mismatch.

\section{Animal data}

In pigs, it has been shown that IAH is associated with a redistribution of blood flow from dependent atelectatic lungs to non-dependent better ventilated lung regions thereby improving ventilation/perfusion matching [41]. This helps to explain why IAH in the context of noninjured lungs only minimally affects oxygenation in animals $[18,19,22]$ and humans [42].

\section{Human data}

Results from a large meta-analysis on 1664 critically ill patients showed that IAH is correlated with the respiratory sequential organ failure subscore [9].

\section{Key message 6: Effect of IAH on oxygenation}

The presence of IAH may result in decreased oxygenation.

\section{Intra-abdominal hypertension and lung injury Pathophysiology}

It is hypothesized that IAH may result in the opening and closing of lung units and this shear stress may result in ventilator-induced lung injury.

\section{Animal data}

Animal studies have shown that increasing IAP during mechanical ventilation may result in cytokine release and subsequent lung injury. Rezende-Neto et al. [43] showed in a study of 50 rats that $60-90 \mathrm{~min}$ of IAH (IAP of $20 \mathrm{mmHg}$ via insufflated intra-peritoneal air) resulted in increased plasma levels of IL-6, increased polymorphonuclear leucocytes activity in lungs as evaluated by myeloperoxidase assay and intense pulmonary inflammatory infiltration including atelectasis and alveolar oedema on lung histology. The level of applied PEEP is not mentioned. Schachtrupp et al. [44] showed in a study of 12 pigs that $24 \mathrm{~h}$ of IAH (IAP of $30 \mathrm{mmHg}$ ) also resulted in histological findings similar to those found in lung injury (interstitial and alveolar leucocytes and fibrin) but also proximal tubular and paracentral necrosis in kidneys and the liver respectively. PEEP of $2 \mathrm{cmH}_{2} \mathrm{O}$ was applied. In a rat model of ARDS, IAH (15 mmHg) was associated with increased inflammation and fibrogenesis [45]. Lima et al. [46] found in a study of 20 rats that a 3-h exposure to an IAP of $15 \mathrm{mmHg}$ was sufficient to cause alveolar collapse, haemorrhage, interstitial oedema, and neutrophil in infiltration in the lungs and increased lung cell apoptosis despite application of lung-protective ventilation.

\section{Human data}

No human data is available whether IAH is a promotor of ventilator-induced lung injury. It is likely that low transpulmonary pressures in the context of IAH can promote shear stress with increased repetitive opening and closing of alveoli units, even when protective tidal volume is used [47].

\section{Key message 7: Effect of IAH on VILI}

The presence of IAH may add to the development of VILI.

\section{Summary effects of IAH on respiratory function}

In summary, the effects of IAH on respiratory function can be characterized by a decrease in lung volumes and chest wall compliance and an increase in airway pressures. Transmission of abdominal pressures to the thoracic cavity is estimated between 20 and $60 \%$, but more human data is required. IAH diminishes abdominal lymphatic drainage. The presence of IAH may impair ventilation and oxygenation. Although IAH is associated with lung injury, the exact mechanism is yet not fully understood. 


\section{Respiratory effect of IAH in the context of specific medical conditions Obesity}

Studies have shown that obese patients with a body mass index higher than $35-40 \mathrm{~kg} / \mathrm{m}^{2}$ have higher IAP values compared to non-obese patients [25, 48]. Similarly, to patients with IAH, the increased IAP values seen in obese patients will equally result in impairment in respiratory mechanics and gas exchange, and decreased lung volumes particularly during sedation, paralysis and mechanical ventilation [49]. As a consequence, the mechanical load exerted on the diaphragm is increased, especially in the supine position both during spontaneous breathing and general anaesthesia [8].

Whereas $C_{\mathrm{CW}}$ accounts in normal conditions for only $15 \%$ of the $C_{\mathrm{RS}}$, this number may increase up to $50 \%$ during patients with obesity or IAH with IAP above $20 \mathrm{mmHg}$ (due to the stiffening of the chest wall) [23, 50-52]. With increasing IAP, both total $C_{\mathrm{RS}}$ and $C_{\mathrm{CW}}$ decrease significantly $[19,22]$. This decrease is more pronounced for the chest wall and shows a strong inverse correlation with IAP [22]. In pigs with injured lungs, IAH has been found to decrease $C_{\mathrm{RS}}$ by decreasing not only $C_{\mathrm{CW}}$ but also $C_{\mathrm{L}}[15,19]$. Anaesthesia of obese patients for non-bariatric surgical procedures requires knowledge of typical comorbidities and their respective treatment options $[49,53]$. A multimodal analgesia approach may be useful to reduce postoperative pulmonary complications [54].

\section{Acute respiratory distress syndrome}

ARDS is a syndrome and not a disease. As a consequence, not all ARDS patients are the same which may be a possible explanation for some conflicting results in previous ARDS studies.

The effect of IAH on the respiratory system appears to be strongly influenced by the presence of lung injury. In pigs with injured lungs, IAH has been found to decrease $C_{\mathrm{RS}}$ by decreasing not only $C_{\mathrm{CW}}$ but also $C_{\mathrm{L}}[15,55]$. Furthermore, only in injured lungs, IAH has a profound effect on oxygenation $[15,55]$. The decrease in $C_{\mathrm{L}}$ and oxygenation in the context of IAH and injured lungs is significant and may help understand some differences found when applying ventilation strategies in patients with IAH. This is also relevant in understanding the pathophysiologic effects of proning in patients with secondary ARDS due to IAH [56].

Ranieri et al. [16] found that patients with ARDS had different respiratory mechanics depending upon the underlying aetiology and the presence of IAH. He found that surgical patients had stiffer chest walls compared to medical patients, probably due to the increased presence of abdominal distension. Respiratory system and chest wall compliance improved after decompressive laparotomy in these patients. Unfortunately, the effect of positive end-expiratory pressure (PEEP), forced residual capacity and IAP was not measured. Mergoni and colleagues [57] studied partitioned respiratory system mechanics and showed that in a subgroup of ARDS patients in which the lower inflection point was mainly determined by $C_{\mathrm{CW}}$ that PEEP was not as effective in improving oxygenation $\left(C_{\mathrm{CW}}\right.$ determined ARDS). However, PEEP was effective in ARDS patients in which the lower inflection point was determined by the $C_{\mathrm{L}}\left(C_{\mathrm{L}}\right.$ determined ARDS),

In contrast to this, Gattinoni et al. [23] showed that primary ARDS resulted in a decreased $C_{\mathrm{L}}$ but normal $C_{\mathrm{CW}}$ $\left(C_{\mathrm{L}}\right.$ determined ARDS) while secondary ARDS presented with preserved $C_{\mathrm{L}}$ but decreased $C_{\mathrm{CW}}\left(C_{\mathrm{CW}}\right.$ determined ARDS), and PEEP allows to recruit lung units only in secondary but not in primary ARDS. In this study the patients with secondary ARDS had IAH as opposed to the patients with primary ARDS [23]. The results imply that the application of PEEP in pulmonary ARDS without IAH may cause over-distension of already open lung units, making these patients more prone to ventilator-induced lung injury than patients with secondary ARDS and IAH. The differences found between these two studies can in part be explained by the difference in measurement manoeuvres and techniques as well as the assumptions used [23, 57].

The same phenomenon may be responsible for the change in respiratory mechanics seen in morbidly obese patients [52]. Therefore, measuring IAP may provide an easy bedside method to estimate altered chest wall mechanics and avert the need to measure oesophageal pressure (see below). IAP also influences the shape of the pressure-volume curve (with downward flattening and rightward shifting) of the total respiratory system and the chest wall while the lung mechanics remain unaffected [15].

In summary, the presence of lung injury appears to strongly influence how IAH affects respiratory mechanics and oxygenation. Ideally, IAP is measured in ARDS patients enrolled in clinical trials to account for any influence of potential coexisting IAH.

\section{Polycompartment syndrome}

The abdominal compartment has unique effects because it is anatomically situated "up-stream" from the extremities and "down-stream" from the thorax and the cranium [7]. Therefore, IAH may influence the physiology and pathophysiology of each of these other compartments. Because the abdomen plays a major role in the interactions between different compartments, IAP affects portal and hepatic vein pressure hence facilitating blood shunting away from the lungs, sometimes referred to 


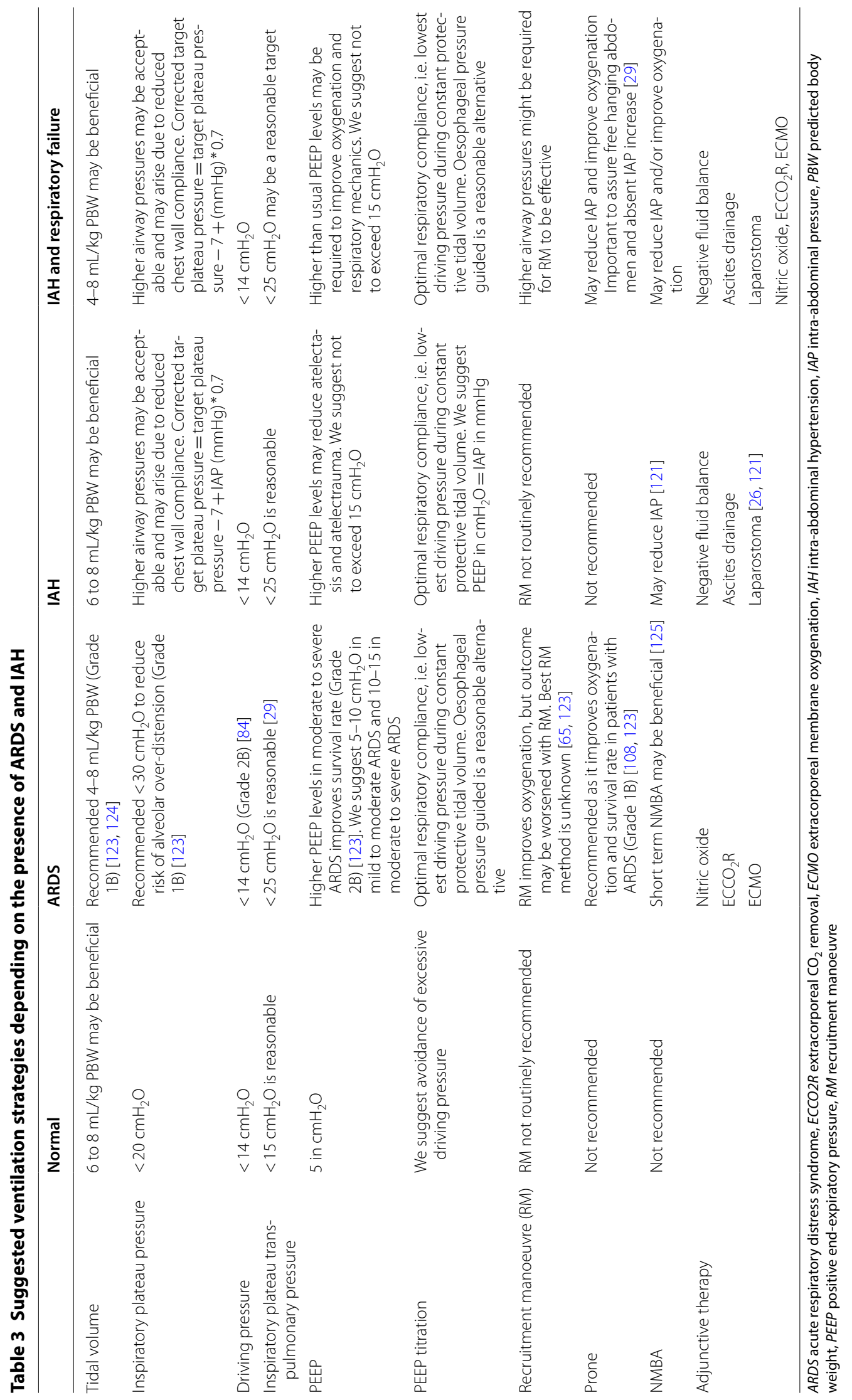


as hepato-abdominal-pulmonary syndrome [7]. Similarly, IAP has been identified as the missing link triggering renal failure (via increased renal vein pressures) in patients with chronic congestive heart disease, referred to as cardio-abdominal-renal syndrome [58]. Likewise, deteriorating kidney function in patients with liver cirrhosis is called hepato-abdominal-renal syndrome.

\section{Practical implications at the bedside and respiratory management in intra-abdominal hypertension}

Table 3 lists suggested ventilation strategies for patients with IAH and ARDS.

\section{Measuring intra-abdominal pressure}

The easiest way to assess IAP in clinical practice is by measuring bladder pressures $[1,59,60]$. The reference standard for intermittent IAP measurement is via the bladder with a maximal instillation volume of $25 \mathrm{~mL}$ of sterile saline and IAP should be measured at end-expiration in the supine position after ensuring that abdominal muscle contractions are absent and with the transducer zeroed at the level of the midaxillary line.

Although abdominal contractions can falsely increase IAP values, we don't recommend increasing sedation or using neuromuscular blocking agents to improve accuracy of IAP measurements. In our clinical experience, IAP can be accurately measured in patients that either receive assisted breaths during mechanical ventilation or don't have any respiratory support. It is important however to sufficiently extend the observation period in order to capture the lowest end-expiratory pressure during which abdominal contractions are clinically (visible and palpable) absent.

\section{Measuring oesophageal pressure}

From dividing the tidal volume by the difference between plateau pressure and positive end-expiratory pressure (driving pressure), $C_{\mathrm{RS}}$ can be calculated. By using an oesophageal catheter (as surrogate for intra-thoracic pressure), $C_{\mathrm{CW}}$ and $C_{\mathrm{L}}$ can also be estimated. In addition, trans-pulmonary pressures is the difference between airway and pleural pressures and is thought to be the main determinant in causing ventilator-induced lung injury $[29,30]$.

However, measuring oesophageal pressure is not easy due to some practical problems at the bedside $[8,61]$. It requires a small air-filled balloon that can transmit the oesophageal pressure via catheter to a pressure transducer. Newer oesophageal catheters are integrated in to a nasogastric feeding tube. The catheter is first placed into the stomach, then withdrawn back into the oesophagus and requires an occlusion test to confirm the correct placement. In addition, the catheters are prone to underand overestimate oesophageal pressures if to little or too much air is instilled. In some patients correct placement is not possible.

\section{Recruitment manoeuvres}

A recruitment manoeuvre (RM) uses a dynamic and transient increase in the trans-pulmonary pressure to open non-aerated or poorly aerated lung areas [62]. The benefit of improved oxygenation may be offset by a potential epithelial and endothelial cell damage and increased alveolar-capillary permeability $[63,64]$. Furthermore, in a recent large randomized controlled trial patients with ARDS receiving RM and PEEP titrated to their best respiratory system compliance (lowest driving pressure during constant protective tidal volumes) as opposed to no RM and low PEEP to had a reduced survival rate [65].

Frequently a fast $\mathrm{RM}$ manoeuvre is performed by applying $40 \mathrm{cmH}_{2} \mathrm{O}$ inspiratory pressure for $40 \mathrm{~s}$ (40-by40 manoeuvre) $[66,67]$.

However, in recent years, following the results of several experimental studies [67-70] and clinical trials [66, 71] slow RM are preferred over fast RM since this is associated with improved oxygenation, less inflammation, and improved haemodynamical instability.

In principle, slow RM are performed by gradually increasing and then decreasing PEEP and/or tidal volumes until plateau pressures of between 40 and $50 \mathrm{cmH}_{2} \mathrm{O}$ are achieved while up keeping tidal ventilation $[66,72]$.

It is estimated that a trans-pulmonary opening pressure equal to $30 \mathrm{cmH}_{2} \mathrm{O}$ is required to open atelectasis. In the setting of IAH with altered $C_{\mathrm{L}} / C_{\mathrm{RS}}$ ratio from 0.85 to 0.5 the resulting trans-pulmonary pressure during a 40-by40 recruitment manoeuvre may only be $20 \mathrm{cmH}_{2} \mathrm{O}$, hence the alveolar units with long time constants would remain collapsed [61]. Therefore, in the setting of IAH, higher opening pressures closer to may be required [29]. The rational for adding IAP in $\mathrm{cmH}_{2} \mathrm{O} / 2$ is due to the ATT being around 50\% [18, 19, 22, 24, 27, 55]. However, applying higher inspiratory opening pressures during a RM is more likely to cause haemodynamic compromise. Therefore, RM should only if at all be applied in haemodynamically stable patients (e.g. not preload dependent) and their blood pressure needs to be closely monitored if RM is applied.

In summary, no studies have been performed in patients with IAH assessing different RM methods. We therefore suggest to use RM manoeuvres with caution in patients with IAH. 


\section{Ventilator settings during lung-protective ventilation in patients with IAH}

It is generally recommended to provide protective lung ventilation in patients with IAH and ARDS [29]. Even in patients with non-injured lungs, protective lung ventilation is becoming more frequently applied as this has been associated with less inflammation and fewer pulmonary complications [73].

\section{Tidal volumes}

There are no studies assessing optimal tidal volumes in patients with IAH. In a rat model of ARDS and IAH (15 mmHg), Santos et al. [45] found that $10 \mathrm{~mL} / \mathrm{kg}$ as opposed to $6 \mathrm{~mL} / \mathrm{kg}$ was associated with reduced inflammation in the subgroup with extrapulmonary ARDS and increased inflammation in the subgroup with pulmonary ARDS. However, there are many studies demonstrating high tidal volumes in patients with ARDS worsens outcome [74].

The perioperative use of lower tidal volumes $(6-8 \mathrm{~mL} /$ $\mathrm{kg}$ of predicted body weight) plus the application of PEEP as opposed to the use of higher tidal volumes (10-12 $\mathrm{mL} / \mathrm{kg}$ of predicted body weight) and no PEEP is associated with reduced respiratory complications in patients undergoing major abdominal surgery [73]. However, other studies and meta-analysis showed that, even in clinical conditions characterized by higher IAH, the reduction in tidal volume and not higher PEEP per se was associated with improved postoperative outcome [75, 76].

In the absence of any evidence regarding optimal tidal volumes in patients with IAH, it is not unreasonable to apply lung-protective ventilation with low tidal volume of $6-8 \mathrm{~mL} / \mathrm{kg}$ of predicted body weight also in all patients with IAH and particularly in patients with IAH and lung injury.

\section{Airway pressures}

Lung-protective ventilation implies opening the lungs with a RM (appropriate high alveolar pressures) and keeping the lungs open (with appropriate PEEP setting) [77]. The altered lung mechanics in the context of IAH may require higher than usual pressures to open airways and keep airways open exceeding those set out in current guidelines [55]. Lung-protective ventilation is recommended using an upper limit goal for plateau pressures of $30 \mathrm{cmH}_{2} \mathrm{O}$ in patients with severe ARDS [78]. These recommendations don't take IAP into account. The rationale behind limiting the plateau pressure is to avoid increased trans-pulmonary pressures, alveolar over-distension and ultimately ventilator-induced lung injury [79].
Ideally, to avoid alveolar over-distension one would measure oesophageal pressure in critically ill patients and aim for inspiratory trans-pulmonary pressures $<25 \mathrm{cmH}_{2} \mathrm{O}$ respectively $[29,61,79,80]$. However, oesophageal pressure measurements are not easy to perform and challenging [61, 81].

As stated above, IAH is associated with raised airway pressures. ATT is around 50\% affecting oesophageal and airway pressures similarly $[19,22,31]$. This means that in the context of IAH, when applying appropriate PEEP levels and lung-protective tidal volumes of $6 \mathrm{~mL} /$ $\mathrm{kg}$ PBW, plateau pressure can exceed the recommended $30 \mathrm{cmH}_{2} \mathrm{O}$ without necessary affecting trans-pulmonary pressures.

It follows that in the presence of IAH airway pressures could be corrected by using ATT. In critically ill subjects IAP is on average $10 \mathrm{mmHg}=13.6 \mathrm{cmH}_{2} \mathrm{O}$ [4, $9,82]$ and we can hypothesize that half of this pressure is normally transmitted in the presence of normal chest wall. Thus, corrected plateau pressure target in $\mathrm{cmH}_{2} \mathrm{O}$ may be calculated as follows: plateau pressure target in $\mathrm{cmH}_{2} \mathrm{O}+[(\mathrm{IAP}$ in $\mathrm{mmHg} * 1.36)-13.36$ (normal IAP in critical patients)]/2 or simplified: plateau pressure target $-7+0.7$ * IAP in $\mathrm{mmHg}$.

For example, for a target plateau pressure of $30 \mathrm{cmH}_{2} \mathrm{O}$ and an IAP of $20 \mathrm{mmHg}$ the corrected target plateau pressure would be: $30-7+0.7 * 20 *=37 \mathrm{cmH}_{2} \mathrm{O}$. In the absence of IAH, plateau pressures target would not require any correction. For example, for target plateau pressure of 30 and IAP $10 \mathrm{mmHg}$ the corrected plateau pressure target would be $23+10 * 0.7=30 \mathrm{cmH}_{2} \mathrm{O}$.

In summary, although higher airway pressures might be acceptable in ARDS patients with IAH we are lacking any supporting clinical data to make any recommendations.

\section{Driving pressure}

In more recent years, driving pressure (pressure difference between plateau airway pressure and PEEP) as a measure of protective lung ventilation has gained more attention.

Driving pressure appears to be helpful to optimize tidal volume and to avoid excessive dynamic strain. Using data from nine randomized trials and a total of 3562 patients with ARDS, it has been demonstrated that the driving pressure has a greater influence on mortality than plateau airway pressure, tidal volume or PEEP [83]. A large international observational study of 29,144 ventilated patients found that a driving pressure of less than $14 \mathrm{cmH}_{2} \mathrm{O}$ is associated with improved hospital survival in patients with ARDS [84]. In obese ARDS patients however, an increased driving pressure was not associated with an increased mortality [85]. No studies specifically assess the effect of different driving pressure on outcome in 
patients with IAH or in obese patients with IAH. However, it is not unreasonable to apply a driving pressure of less than $14 \mathrm{cmH}_{2} \mathrm{O}$ in patients with IAH.

Driving pressure may also be useful in titrating PEEP and has been tested with promising physiological results in obese patients undergoing general anaesthesia [86, 87] and in obese patients with ARDS [88, 89]. An individual patient data meta-analysis showed that obese patients undergoing surgery receiving higher PEEP levels that resulted in an increased driving pressure had more postoperative pulmonary complications [90]. There is currently insufficient data to suggest using driving pressure to titrate PEEP might translate in improved survival of patients with IAH or obesity with or without ARDS. Thus, in our opinion driving pressure should be used to avoid excessive PEEP and not to "optimize" (increase) PEEP.

\section{PEEP}

To date, the best PEEP to be used in the setting of IAH remains unknown [91]. As stated above, in the setting of IAH the lung will collapse at higher closing pressures during expiration. There remains the fear that in the context of IAH, increased atelectrauma (also referred to as atelectotrauma) due to increased atelectasis formation and an insufficient PEEP may contribute to the lung injury found in the presence of IAH $[8,47,92]$. Therefore, higher PEEP levels might be required to keep lungs open and reduce lung injury in the context of IAH. In contrast to this, higher PEEP levels may not only have negative haemodynamic effects but also cause lung injury if alveolar over-distension occurs [44, 92].

Different animal studies have examined different levels of PEEP in the setting of IAH. A first study was conducted in 13 pigs with healthy lungs and IAH was created with an inflatable balloon, the PEEP levels $(5,8,12$ and $15 \mathrm{cmH}_{2} \mathrm{O}$ ) were unmatched to the level of IAP [18]. The conclusions were that commonly applied PEEP levels, set below the IAP level may not prevent end-expiratory lung volume decline. Noteworthy was that IAP reached $18 \mathrm{mmHg}$ or thus $25 \mathrm{cmH}_{2} \mathrm{O}$, while PEEP was only set up to a maximum of $15 \mathrm{cmH}_{2} \mathrm{O}$. In a second study, conducted in 9 pigs with healthy lungs, IAH was again created with an inflatable balloon, the PEEP levels were now matched for IAP [19]. The authors found preservation of end-expiratory lung volume without improvement in arterial oxygen tension but with a reduction in $\mathrm{CO}$. In a third study, conducted in 8 pigs with lung injury induced by saline lavage and IAH created with $\mathrm{CO}_{2}$ insufflation up to $20 \mathrm{mmHg}$, the PEEP levels $\left(27 \mathrm{cmH}_{2} \mathrm{O}\right)$ were matched for IAP [93]. The major findings during PEEP application were lower inflection point, improved compliance, decreased alveolar-arterial gradient and less shunt. In a fourth animal study in 9 pigs, IAH induced by an inflatable balloon was combined with oleic acidinduced lung injury, and PEEP levels were matched to IAP [55]. The authors found better end-expiratory lung volumes, lower shunt fraction, lower dead space and a better oxygenation.

There are only few clinical studies. Krebs et al. [94] examined different levels of PEEP in 20 patients with ARDS, ten had normal (IAP of $8 \mathrm{mmHg}$ ) and $10 \mathrm{had}$ grade II IAH (IAP of $16 \mathrm{mmHg}$ ). No difference was found between the groups at baseline. This might explain why no differences were found between the groups regarding the effect of higher levels of PEEP on lung mechanics or oxygenation.

In a different study Krebs et al. [95] examined two methods of PEEP titrated in 13 patients with moderate to severe ARDS. They found that in patients with IAH, the best PEEP set according to the best compliance of the respiratory system, is not always associated with positive end-expiratory trans-pulmonary pressure.

Gattinoni et al. [23] applied different levels of PEEP $\left(5,10,15\right.$, and $\left.20 \mathrm{cmH}_{2} \mathrm{O}\right)$ in patients with ARDS. The patients with extrapulmonary ARDS had IAH (IAP of $16 \mathrm{mmHg}$ ) and PEEP improved $C_{\mathrm{RS}}$ due to a reduction in $C_{\mathrm{CW}}$. In contrast, the patients with pulmonary ARDS had normal IAP $(4 \mathrm{mmHg})$ and PEEP worsened $C_{\mathrm{RS}}$ due to an increase in $C_{\mathrm{L}}$.

Talmor et al. $[29,96]$ found that IAP (measured via the stomach) and oesophageal pressure (measured via an oesophageal balloon) closely correlated. Therefore, not only opening pressures but also closing pressures are increased during IAH and as such higher PEEP levels may be required to prevent end-expiratory lung collapse.

In a pilot study of 15 patients with IAH (IAP of $17 \mathrm{mmHg}$ ), different levels of PEEP were applied that were matched to the level of IAP [97]. In contrast to PEEP $=50 \%$ of IAP, PEEP $=100 \%$ of IAP (both parameters measured in equal units) was not well tolerated due to hypoxaemia, hypotension or endotracheal cuff leak.

It is difficult to draw any conclusions from these experimental and clinical studies. In principle, it makes sense to apply higher PEEP levels in the context of IAH. Furthermore, it is appealing to apply an easy to use bedside formula for setting the PEEP level in patients with IAH, e.g. PEEP $\left(\mathrm{cmH}_{2} \mathrm{O}\right)$ to be set to the level of IAP ( $\left.\mathrm{mmHg}\right)$.

There is a concern that increasing PEEP can increase IAP. Many published studies found PEEP to have only minimal influence on IAP (increasing PEEP from as low as 0 to as high as $15 \mathrm{cmH}_{2} \mathrm{O}$ and average IAP increase of $1 \mathrm{mmHg}$ ) [25]. In contrast to this, Verzilli et al. [98] examined the effect of raising PEEP from 0 to $12 \mathrm{cmH}_{2} \mathrm{O}$ in 30 patients with ARDS and found that IAP increased 
predominantly in patients with IAH (i.e. IAP increased from 15 to $20 \mathrm{cmH}_{2} \mathrm{O}$ ).

In summary, while PEEP can counteract the negative effects of IAH on lung volume and chest wall compliance, there is no evidence that a certain PEEP level improves outcome in patients with IAH. In the absence of any evidence we recommend to set the PEEP according to the best respiratory system compliance [92].

\section{IAH mode of ventilation and assisted breathing}

Assisted breathing is the most common type of ventilation in critically ill patients [99] and even in patients with ARDS [84]. The potential advantages of assisted breathing include less need of sedation and haemodynamic impairment, minimal muscular atrophy, better lymph drainage and regional organ perfusion $[36,100]$.

Little is known about the optimal ventilation mode to be applied in patients with IAH but some experimental data exist. Several experimental evidences of ARDS without IAH showed reduced lung injury during assisted ventilation [101-104]. Recent results from an animal experiment suggests that assisted ventilation might be associated with improved oxygenation and less lung injury and inflammation in mild to moderate (extrapulmonary) ARDS in the presence of IAH (15 $\mathrm{mmHg})$ [105]. This was likely due to reduced atelectasis and more homogeneous distribution of regional ventilation. However, other experimental evidence reported that addition of unsupported spontaneous breaths to BiPAP did not improve haemodynamic and respiratory function and caused greater histopathologic damage to the lungs, in the presence of severe IAH [106]. The difference in these results may be due to the amount of inspiratory effort reached during spontaneous breathing and/or different modalities of ventilation.

In conclusion, we suggest a cautious use of assisted ventilation in patients, especially if in the presence of severe IAH.

\section{Prone and other positioning}

Prone position improves respiratory mechanics, oxygenation and reduces over-distension [107]. Prone ventilation has been shown to improve outcome in patients with severe ARDS [108]. Placing ARDS patients in the prone or upright position does not result in univocal beneficial effects on respiratory mechanics and oxygenation parameters [52].

In the setting of IAH, there seems to be some merit by suspending and offloading the abdomen during prone ventilation. Mure et al. [109] demonstrated in an interesting animal model that the prone position improves pulmonary gas exchange to a greater degree in the presence of IAH as shown by increases in $\mathrm{PaO}_{2}$ and decreases in ventilation perfusion heterogeneity. The observed decrease in IAP (estimated via gastric pressure), resulting in a concomitant decrease in pleural pressure in the prone position may be a possible explanation for these observations, hence facilitating regional ventilation in the dependent lung zones near the diaphragm.

In a recent experimental study in 12 pigs that underwent pulmonary saline lavage and injurious ventilation to simulate ARDS, the authors showed that prone position and PEEP independently improved lung compliance without interaction [110]. As expected, IAH (15 $\mathrm{mmHg}$ ) increased the PEEP needed for the best lung compliance. However, best PEEP was not significantly different between prone $\left(12.8 \pm 2.4 \mathrm{cmH}_{2} \mathrm{O}\right)$ and supine $\left(11.0 \pm 4.2 \mathrm{cmH}_{2} \mathrm{O}\right)$ positions when targeting lung compliance.

De Jong et al. [111] successfully applied prone positioning in obese and non-obese patients with ARDS. In obese patient, oxygenation improved significantly more than in non-obese patients. Although not measured, these obese patients would likely have had higher IAP levels.

Placing patients with ARDS in the prone position either does not change or only has mild influence on IAP levels with more pronounced effects in patients with IAH $[25,112]$. For example, Jozwiak et al. [112] found a mild increase in IAP from 15 to $18 \mathrm{mmHg}$ when patients with ARDS were proned.

The use of chest and pelvic suspension has a large influence on IAP pressures [113]. The pressure exerted by the chest suspension will result in a decreased $C_{\mathrm{CW}}$, while the suspension at the level of the symphysis pubis will ensure a free suspended abdomen and thereby limiting transmission of IAP towards the dorsobasal lung regions and diaphragm. This decreases IAP and improves abdominal compliance and reduces atelectasis via dorsobasal recruitment. The theoretical benefits of proning a patient with IAH need to be outweighed against the practical risks (e.g. patients with an open abdomen).

Interestingly, weightlessness appears to be beneficial in the setting of IAH [114]. The combination of a weight placed on the chest with a vacuum shell placed on the abdomen has similar effects to that of weightlessness with reducing $C_{\mathrm{CW}}$ and improving abdominal compliance (Fig. 4).

In summary, prone position appears to not increase IAP and likely improve oxygenation in patients with respiratory failure and IAH. However, further studies are required to compare the effectiveness on outcome of these different approaches in patients with IAH and respiratory failure. 


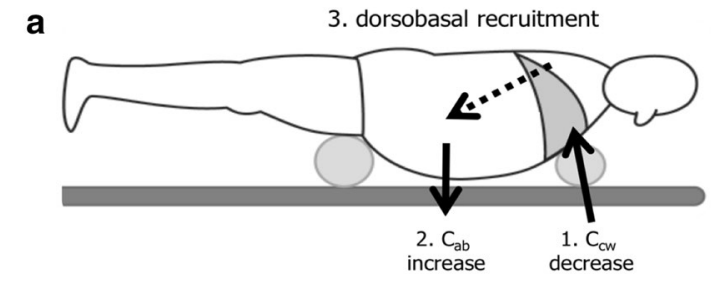

b

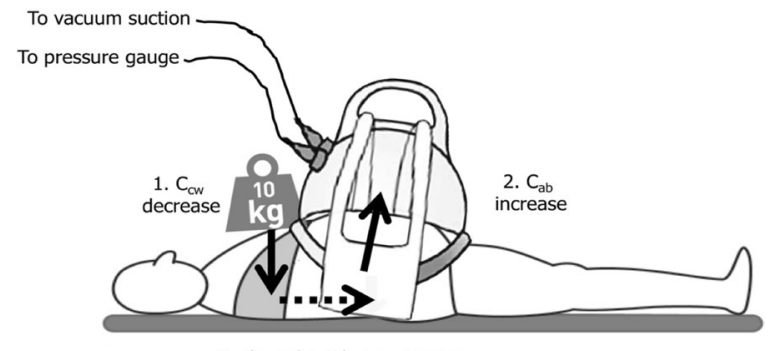

3. dorsobasal recruitment

Fig. 4 Effects of positioning on chest and abdominal wall compliance. a Effects of prone positioning with abdominal suspension on chest and abdominal wall compliance. The suspension placed under the chest will reduce chest wall compliance (1) while the abdominal suspension placed at the level of the symphysis will exert a gravitational effect that will increase abdominal wall compliance (2). This will result in recruitment of dorsobasal lung regions (3). $\mathbf{b}$ Effects of supine positioning in combination with weight placed on the chest and vacuum bell on the abdomen. The weight placed on the chest will reduce chest wall compliance (1) while the abdominal vacuum bell will increase abdominal wall compliance (2). This will result in recruitment of dorsobasal lung regions (3)

\section{Potential haemodynamic compromise in patients with IAH and the application of PEEP}

\section{Individual cardiovascular effect of IAP and PEEP}

The individual effect of IAH as well as high PEEP on the cardiovascular system is well described [115-118]. Both IAH and high PEEP are associated with a reduced cardiac output. IAH decreases venous return mainly by abdominal compression of the inferior vena cava but central vascular filling pressures like central venous pressure and pulmonary artery occlusion pressure are elevated. Intra-thoracic pressure via ATT is elevated thereby raising right ventricular afterload. Left ventricular afterload is increased due to a direct compression of the abdominal capillary vessels and via an activation of the renin-angiotensin-aldosterone pathway. It is thought that in patients with IAH, cardiac output is mainly influenced by afterload [116].

PEEP exerts its cardiovascular influence by increasing intra-thoracic pressures [117]. Right and left ventricular venous return is reduced, right ventricular afterload is increased but left ventricular afterload is decreased.

\section{Combined cardiovascular effect of IAP and PEEP}

Not much studies have assessed the combined haemodynamic effect of both IAP and PEEP. Both IAP and PEEP synergistically decrease increase right ventricular afterload. In theory, IAP and PEEP have two possible antagonistic interactions. Firstly, left ventricular afterload is increased by IAH but decreased by high PEEP levels.

Secondly, venous return from inferior vena cava to the right atrium is largely determined by the right atrial pressure (RAP) over IAP gradient [119].

In the absence of IAH (RAP > IAP), increasing IAP levels can increase venous return and improve cardiac output by redistribution of blood from the abdominal to the thoracic compartment. In the presence of IAH however $(\mathrm{RAP}<\mathrm{IAP})$, venous return and cardiac output are reduced. It is possible that increasing PEEP in the presence of IAH might favourably change the RAP over IAP gradient (RAP > IAP) and thereby improving both venous return and cardiac output.

There are only a few animal and human studies examining combined haemodynamic effect of IAH and PEEP. In animal studies PEEP (ranged of 4-22 $\mathrm{mmHg}$ ) had a stronger negative impact on cardiac output than IAP (range of up to $26 \mathrm{mmHg}$ ) $[18,19,55]$. PEEP that was adjusted to half the IAP (PEEP $=50 \%$ of IAP) did not significantly reduce cardiac output in contrast to PEEP that was fully adjusted to IAP.

Krebs et al. [94] applied different PEEP levels of up to $15 \mathrm{mmHg}\left(20 \mathrm{cmH}_{2} \mathrm{O}\right)$ in 20 patients with ARDS but did not find any cardiovascular differences between the patients with and without IAH.

In a pilot study of 15 patients with IAH but healthy lungs, different PEEP levels were applied and no difference in blood pressure or heart rate was found probably due to small sample size [97].

In 8 volunteers with inflated medical anti-shock trousers (IAP not measured), additional PEEP of $10 \mathrm{cmH}_{2} \mathrm{O}$ was applied and echocardiography was performed [120]. It was concluded that the increase in left ventricular afterload induced by medical anti-shock trousers inflation may be counteracted by the use of a PEEP.

In summary, limited experimental and clinical data suggest that the negative haemodynamic effect of PEEP is to some degree counteracted in patients with IAH. However, it is difficult to draw any conclusions from above studies and the clinician should be cautious when applying higher PEEP levels in patients with IAH as cardiovascular response to higher PEEP levels is difficult to predict. 


\section{IAH / ACS MEDICAL MANAGEMENT ALGORITHM}

- The choice (and success) of the medical management strategies listed below is strongly related to both the etiology of the patient's IAH / ACS and the patient's clinical situation. The appropriateness of each intervention should always be considered prior to implementing these interventions in any individual patient.

- The interventions should be applied in a stepwise fashion until the patient's intra-abdominal pressure (IAP) decreases.

- If there is no response to a particular intervention, therapy should be escalated to the next step in the algorithm.

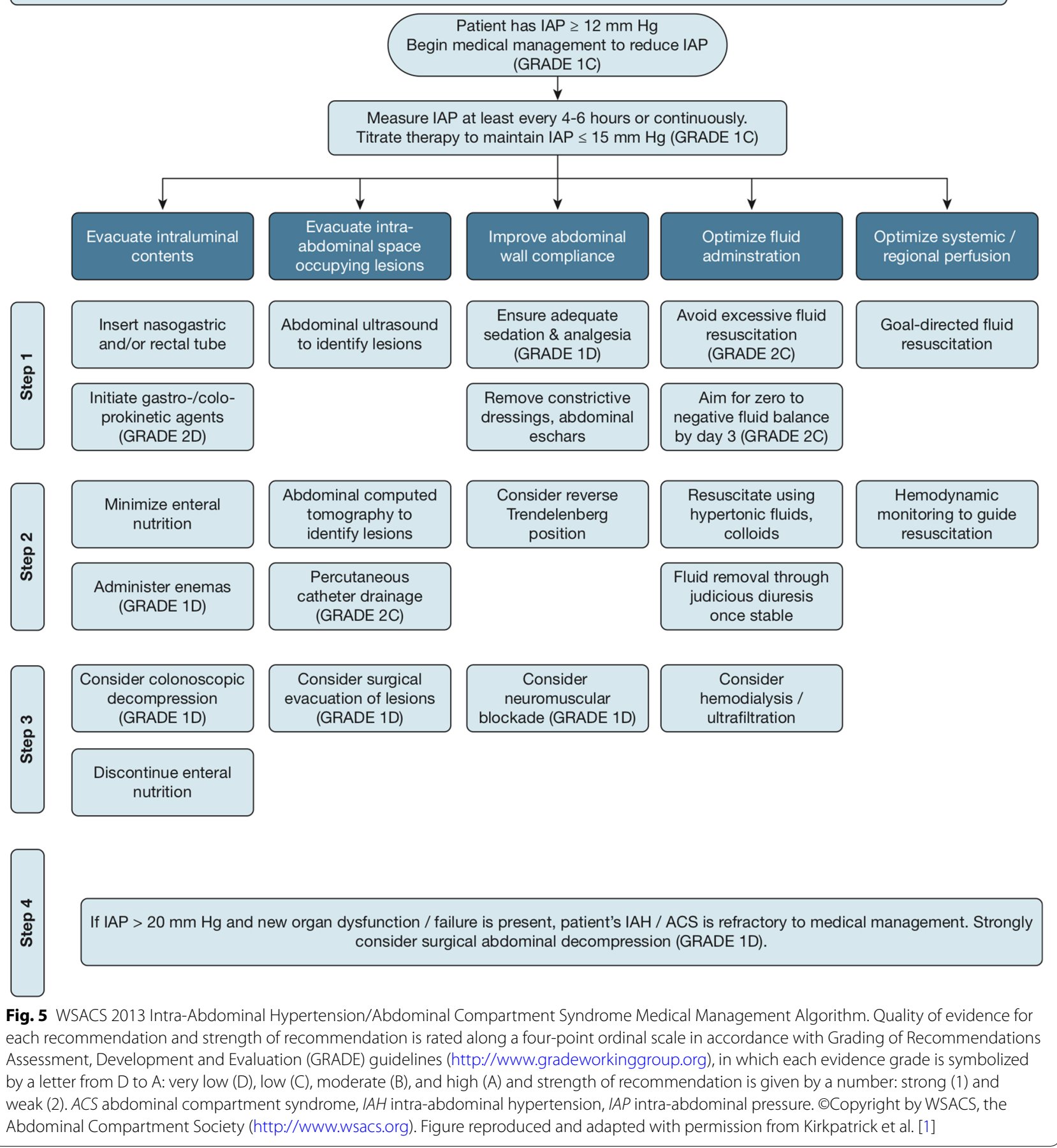




\section{Medical management of intra-abdominal hypertension}

Medical management strategies for raised IAP may be divided into five categories according to their proposed mechanism of action. First, improvement of abdominal wall compliance (sedation and analgesia, neuromuscular blockade, epidural anaesthesia and body positioning changes); second, evacuation of intra-luminal contents (nasogastric or rectal decompression and use of prokinetic agents); third, drainage of intra-abdominal fluid collections (paracentesis or percutaneous catheter drainage); fourth, avoidance of excessive fluid resuscitation and correction of a positive patient fluid balance (with judicious use of fluids, e.g. rather hypertonic solutions instead of crystalloids); and fifth, organ support (respiratory and cardiovascular monitoring as outlined above) [1, $121,122]$. It would be beyond the scope of this review to discuss the different medical management strategies into detail. An overview of the WSACS IAH/ abdominal compartment syndrome medical management algorithm (and the associated GRADES of recommendations) is shown in Fig. 5. Specific to patients with IAH requiring mechanical ventilation, it is worth noting that small reductions in intra-abdominal volume can significantly improve airway pressure and IAP [26].

Monitoring extravascular lung water and pulmonary vascular permeability (calculated with trans-pulmonary thermodilution and defined as EVLW divided by pulmonary blood volume) can provide useful additional information. Deep sedation with a short course of neuromuscular blocking agents may be useful in selected patients or as a bridge towards decompressive laparotomy.

\section{Conclusions}

Although considerable progress has been made over the past decades, some important questions remain relating to the optimal ventilation management in patients with IAH. When looking after patients with IAH and ARDS requiring mechanical ventilation, an important first step is to measure IAP and aim to reduce IAP in order to reduce airway pressures keeping in mind that small reductions in intra-abdominal volume can significantly reduce IAP and airway pressures [26].

Although challenging, the measurement of oesophageal pressure as surrogate for intra-thoracic pressure can provide trans-pulmonary pressures that can help guide ventilation [92]. It is of note that IAH can lead to the polycompartment syndrome with the associated interactions between different compartmental pressures [7]. Within this respect, one should avoid head of bed elevation above $45^{\circ}$ in patients with high body mass index as this is associated with increase in IAP.
During lung-protective ventilation, we recommend the application of protective lung ventilation with low tidal volumes of $6-8 \mathrm{~mL} / \mathrm{kg}$ and maximum driving pressure of $15 \mathrm{cmH}_{2} \mathrm{O}$. Higher than recommended plateau pressures of $30 \mathrm{cmH}_{2} \mathrm{O}$ might be required in the setting of IAH. Taking normal IAP of $10 \mathrm{mmHg}$ and ATT of around 50\% into account, $23 \mathrm{cmH}_{2} \mathrm{O}+0.7$ *IAP in $\mathrm{mmHg}$ might be an appropriate upper limit of plateau pressure.

In addition, in patients with IAH, higher PEEP levels might be required to prevent end-expiratory lung collapse. However, the best PEEP in the setting of IAH is still unknown. Pressure-volume loops or the use of oesophageal pressure might be useful to determine the best PEEP in patients with IAH. Knowing that the ATT is around $50 \%$, it may be appropriate to set PEEP $\left(\mathrm{cmH}_{2} \mathrm{O}\right)$ equal to $50 \%$ of IAP in $\mathrm{cmH}_{2} \mathrm{O}$. In the absence of any evidence, we recommend to set the PEEP according to the best $C_{\mathrm{RS}}$.

Anti-Trendelenburg or prone position with abdominal suspension may have beneficial effects on respiratory mechanics in patients with IAH. Monitoring the respiratory function and adapting the ventilator settings accordingly during anaesthesia and critical care is of great importance.

With our improved understanding of the pathophysiology and epidemiology, future randomized studies should be focused on defining whether targeted or multifaceted medical (and minimally invasive surgical) interventions aimed at reducing IAP and improving abdominal compliance will ultimately improve outcomes in patients with IAH and abdominal compartment syndrome.

\section{Abbreviations \\ ARDS: acute respiratory distress syndrome; ATT: abdominal-thoracic transmis- sion; $C_{R S}$ : total respiratory system compliance; $C_{C W}$ : chest wall compliance; $C_{\perp}$ : lung compliance; EVLW: extravascular lung water; $\mid \mathrm{AH}$ : intra-abdominal hypertension; IAP: intra-abdominal pressure; ICU: intensive care unit; PEEP: positive end-expiratory pressure; RAP: right atrial pressure; RM: recruitment manoeuvre.}

\section{Authors' contributions}

MM wrote the concept. AR wrote the first draft. PP and MM reviewed and edited the manuscript. All authors read and approved the final manuscript.

\section{Authors' information}

Dr. Manu Malbrain is professor at the faculty of Medicine and Pharmacy at the Vrije Universiteit Brussels (VUB) and member of the Executive Committee of the Abdominal Compartment Society, formerly known as the World Society of Abdominal Compartment Syndrome (https://www.wsacs.org/). He is founding President of WSACS and current Treasurer. He is co-founder of the International Fluid Academy (IFA). The IFA is integrated within the not-for-profit charitable organization iMERiT, International Medical Education and Research Initiative, under Belgian law. The content of the IFA website (http://www.fluid academy.org) is based on the philosophy of FOAM (Free Open Access Medical education-\#FOAMed). The site recently received the HONcode quality label for medical education (https://www.healthonnet.org/HONcode/Condu ct.html?HONConduct519739). 


\begin{abstract}
Author details
${ }^{1}$ Department of Intensive Care, Fiona Stanley Hospital, Murdoch Drive, Murdoch, WA 6152, Australia. ${ }^{2}$ Medical School, Division of Emergency Medicine, The University of Western Australia, Sterling Highway, Crawley, Perth, WA 6009 Australia. ${ }^{3}$ Medical School, The Notre Dame University, Henry Road, Fremantle, Perth, WA 6959, Australia. ${ }^{4}$ Department of Surgical Sciences and Integrated Diagnostics, University of Genoa, Genoa, Italy. ${ }^{5}$ San Martino Policlinico Hospital, IRCCS for Oncology and Neurosciences, Genoa, Italy. ${ }^{6}$ Intensive Care Unit, University Hospital Brussels (UZB), Jette, Belgium. ${ }^{7}$ Faculty of Medicine and Pharmacy, Vrije Universiteit Brussel (VUB), Brussels, Belgium.
\end{abstract}

\section{Acknowledgements \\ Not applicable.}

\section{Competing interests}

MM is a member of the medical advisory Board of Pulsion Medical Systems (now fully integrated in Getinge, Solna, Sweden) and Serenno Medical (Tel Aviv, Israel), consults for Baxter, Maltron, ConvaTec, Acelity, Spiegelberg and Holtech Medical. None of the remaining authors have any potential conflict of interest related to the main topic of this article.

\section{Availability of data and material \\ Not applicable.}

\section{Consent for publication}

Not applicable.

\section{Ethics approval and consent to participate}

Not applicable.

\section{Funding}

Not applicable.

\section{Publisher's Note}

Springer Nature remains neutral with regard to jurisdictional claims in published maps and institutional affiliations.

Received: 28 January 2019 Accepted: 4 April 2019

Published online: 25 April 2019

\section{References}

1. Kirkpatrick AW, Roberts DJ, De Waele J, et al. Intra-abdominal hypertension and the abdominal compartment syndrome: updated consensus definitions and clinical practice guidelines from the World Society of the Abdominal Compartment Syndrome. Intensive Care Med. 2013;39:1190-206.

2. Reintam Blaser A, Regli A, De Keulenaer B, et al. Incidence, risk factors, and outcomes of intra-abdominal hypertension in critically ill patients-a prospective multicenter study (IROI study). Crit Care Med. 2019;47:535-42.

3. Wise R, Roberts DJ, Vandervelden S, et al. Awareness and knowledge of intra-abdominal hypertension and abdominal compartment syndrome: results of an international survey. Anaesthesiol Intensive Ther. 2015;47:14-29.

4. Malbrain ML, Chiumello D, Pelosi P, et al. Incidence and prognosis of intraabdominal hypertension in a mixed population of critically ill patients: a multiple-center epidemiological study. Crit Care Med. 2005;33:315-22.

5. Malbrain ML, Peeters $Y$, Wise R. The neglected role of abdominal compliance in organ-organ interactions. Crit Care. 2016;20:67.

6. Blaser AR, Bjorck M, De Keulenaer B, Regli A. Abdominal compliance: a bench-to-bedside review. J Trauma Acute Care Surg. 2015;78:1044-53.

7. Malbrain ML, Roberts DJ, Sugrue M, et al. The polycompartment syndrome: a concise state-of-the-art review. Anaesthesiol Intensive Ther. 2014;46:433-50

8. Pelosi P, Quintel M, Malbrain ML. Effect of intra-abdominal pressure on respiratory mechanics. Acta Clin Belg. 2007;62(Suppl):78-88.
9. Malbrain ML, Chiumello D, Cesana BM, et al. A systematic review and individual patient data meta-analysis on intra-abdominal hypertension in critically ill patients: the wake-up project. World initiative on abdominal hypertension epidemiology, a unifying project (WAKE-Up!). Minerva Anestesiol. 2014;80:293-306.

10. Holodinsky JK, Roberts DJ, Ball CG, et al. Risk factors for intra-abdominal hypertension and abdominal compartment syndrome among adult intensive care unit patients: a systematic review and meta-analysis. Crit Care. 2013:17:R249.

11. Vidal MG, Ruiz Weisser J, Gonzalez F, et al. Incidence and clinical effects of intra-abdominal hypertension in critically ill patients. Crit Care Med. 2008;36:1823-31.

12. Reintam Blaser A, Parm P, Kitus R, Starkopf J. Risk factors for intraabdominal hypertension in mechanically ventilated patients. Acta Anaesthesiol Scand. 2011;55:607-14.

13. Malbrain ML, Chiumello D, Pelosi P, et al. Prevalence of intra-abdominal hypertension in critically ill patients: a multicentre epidemiological study. Intensive Care Med. 2004;30:822-9.

14. Kim IB, Prowle J, Baldwin I, Bellomo R. Incidence, risk factors and outcome associations of intra-abdominal hypertension in critically ill patients. Anaesth Intensive Care. 2012;40:79-89.

15. Quintel M, Pelosi P, Caironi P, et al. An increase of abdominal pressure increases pulmonary edema in oleic acid-induced lung injury. Am J Respir Crit Care Med. 2004;169:534-41.

16. Ranieri VM, Brienza N, Santostasi S, et al. Impairment of lung and chest wall mechanics in patients with acute respiratory distress syndrome: role of abdominal distension. Am J Respir Crit Care Med. 1997;156:1082-91.

17. Mutoh T, Lamm WJ, Embree LJ, Hildebrandt J, Albert RK. Abdominal distension alters regional pleural pressures and chest wall mechanics in pigs in vivo. J Appl Physiol. 1991;70:2611-8.

18. Regli A, Hockings LE, Musk GC, et al. Commonly applied positive endexpiratory pressures do not prevent functional residual capacity decline in the setting of intra-abdominal hypertension: a pig model. Crit Care. 2010;14:R128.

19. Regli A, Chakera J, De Keulenaer BL, et al. Matching positive end-expiratory pressure to intra-abdominal pressure prevents end-expiratory lung volume decline in a pig model of intra-abdominal hypertension. Crit Care Med. 2012;40:1879-86.

20. Mutoh T, Lamm WJ, Embree LJ, Hildebrandt J, Albert RK. Volume infusion produces abdominal distension, lung compression, and chest wall stiffening in pigs. J Appl Physiol. 1985;1992(72):575-82.

21. Zhou JC, Xu QP, Pan KH, Mao C, Jin CW. Effect of increased intra-abdominal pressure and decompressive laparotomy on aerated lung volume distribution. J Zhejiang Univ Sci B. 2010;11:378-85.

22. Wauters J, Claus P, Brosens N, et al. Relationship between abdominal pressure, pulmonary compliance, and cardiac preload in a porcine model. Crit Care Res Pract. 2012;2012:763181.

23. Gattinoni L, Pelosi P, Suter PM, Pedoto A, Vercesi P, Lissoni A. Acute respiratory distress syndrome caused by pulmonary and extrapulmonary disease. Different syndromes? Am J Respir Crit Care Med. 1998;158:3-11.

24. Torquato JA, Lucato JJ, Antunes T, Barbas CV. Interaction between intraabdominal pressure and positive-end expiratory pressure. Clinics (Sao Paulo). 2009:64:105-12.

25. De Keulenaer BL, De Waele JJ, Powell B, Malbrain ML. What is normal intra-abdominal pressure and how is it affected by positioning, body mass and positive end-expiratory pressure? Intensive Care Med. 2009;35:969-76.

26. Regli A, De Keulenaer BL, Singh B, Hockings LE, Noffsinger B, van Heerden PV. The respiratory pressure-abdominal volume curve in a porcine model. Intensive Care Med Exp. 2017;5:11.

27. Cortes-Puentes GA, Cortes-Puentes LA, Adams AB, Anderson CP, Marini $J J$, Dries DJ. Experimental intra-abdominal hypertension influences airway pressure limits for lung protective mechanical ventilation. J Trauma Acute Care Surg. 2013;74:1468-73.

28. Malbrain ML, Roberts DJ, De Laet I, et al. The role of abdominal compliance, the neglected parameter in critically ill patients - a consensus review of 16. Part 1: definitions and pathophysiology. Anaesthesiol Intensive Ther. 2014;46:392-405. 
29. Talmor D, Sarge T, Malhotra A, et al. Mechanical ventilation guided by esophageal pressure in acute lung injury. N Engl J Med. 2008;359:2095-104

30. Marini JJ, Gattinoni L. Ventilatory management of acute respiratory distress syndrome: a consensus of two. Crit Care Med. 2004;32:250-5.

31. Wauters J, Wilmer A, Valenza F. Abdomino-thoracic transmission during ACS: facts and figures. Acta Clin Belg. 2007:62(Suppl 1):200-5.

32. Malbrain ML, Pelosi P, De Laet I, Lattuada M, Hedenstierna G. Lymphatic drainage between thorax and abdomen: please take good care of this well-performing machinery. Acta Clin Belg. 2007;62(Suppl 1):152-61.

33. Moriondo A, Mukenge S, Negrini D. Transmural pressure in rat initial subpleural lymphatics during spontaneous or mechanical ventilation. Am J Physiol Heart Circ Physiol. 2005;289:H263-9.

34. Toens C, Schachtrupp A, Hoer J, Junge K, Klosterhalfen B, Schumpelick $\checkmark$. A porcine model of the abdominal compartment syndrome. Shock. 2002;18:316-21.

35. Tons C, Schachtrupp A, Rau M, Mumme T, Schumpelick V. Abdominal compartment syndrome: prevention and treatment. Chirurg. 2000;71:918-26.

36. Lattuada $M$, Hedenstierna $G$. Abdominal lymph flow in an endotoxin sepsis model: influence of spontaneous breathing and mechanical ventilation. Crit Care Med. 2006;34:2792-8.

37. Malbrain M, Pelosi P. Open up and keep the lymphatics open: they are the hydraulics of the body! Crit Care Med. 2006;34:2860-2.

38. Cordemans C, De Laet I, Van Regenmortel N, et al. Fluid management in critically ill patients: the role of extravascular lung water, abdominal hypertension, capillary leak, and fluid balance. Ann Intensive Care. 2012;2(Suppl 1):S1.

39. Cordemans C, De Laet I, Van Regenmortel N, et al. Aiming for a negative fluid balance in patients with acute lung injury and increased intraabdominal pressure: a pilot study looking at the effects of PAL-treatment. Ann Intensive Care. 2012;2(Suppl 1):S15.

40. Malbrain ML, Marik PE, Witters I, et al. Fluid overload, de-resuscitation, and outcomes in critically ill or injured patients: a systematic review with suggestions for clinical practice. Anaesthesiol Intensive Ther. 2014;46:361-80

41. Strang CM, Freden F, Maripuu E, Hachenberg T, Hedenstierna G. Ventilation-perfusion distributions and gas exchange during carbon dioxidepneumoperitoneum in a porcine model. Br J Anaesth. 2010;105:691-7.

42. Andersson L, Lagerstrand L, Thörne A, Sollevi A, Brodin LA, Odeberg Wernerman S. Effect of $\mathrm{CO}(2)$ pneumoperitoneum on ventilationperfusion relationships during laparoscopic cholecystectomy. Acta Anaesthesiol Scand. 2002;46:552-60.

43. Rezende-Neto JB, Moore EE, Melo de Andrade MV, et al. Systemic inflammatory response secondary to abdominal compartment syndrome: stage for multiple organ failure. J Trauma. 2002;53:1121-8.

44. Schachtrupp A, Lawong G, Afify M, Graf J, Toens C, Schumpelick V. Fluid resuscitation preserves cardiac output but cannot prevent organ damage in a porcine model during $24 \mathrm{~h}$ of intraabdominal hypertension. Shock. 2005;24:153-8.

45. Santos $\mathrm{CL}$, Moraes $\mathrm{L}$, Santos RS, et al. Effects of different tidal volumes in pulmonary and extrapulmonary lung injury with or without intraabdominal hypertension. Intensive Care Med. 2012;38:499-508.

46. Lima R, Silva PL, Capelozzi VL, et al. Early impact of abdominal compartment syndrome on liver, kidney and lung damage in a rodent model. Anaesthesiol Intensive Ther. 2017;49:130-8.

47. Pinhu L, Whitehead T, Evans T, Griffiths M. Ventilator-associated lung injury. Lancet. 2003;361:332-40.

48. Malbrain ML, De Keulenaer BL, Oda J, et al. Intra-abdominal hypertension and abdominal compartment syndrome in burns, obesity, pregnancy, and general medicine. Anaesthesiol Intensive Ther. 2015:47:228-40.

49. Schetz M, De Jong A, Deane AM, et al. Obesity in the critically ill: a narrative review. Intensive Care Med. 2019. https://doi.org/10.1007/s0013 4-019-05594-1.

50. Pelosi P, Croci M, Ravagnan I, et al. Respiratory system mechanics in sedated, paralyzed, morbidly obese patients. J Appl Physiol. 1985;1997(82):811-8.

51. Pelosi P, Croci M, Ravagnan I, et al. The effects of body mass on lung volumes, respiratory mechanics, and gas exchange during general anesthesia. Anesth Analg. 1998;87:654-60.
52. Pelosi P, Croci M, Ravagnan I, Vicardi P, Gattinoni L. Total respiratory system, lung, and chest wall mechanics in sedated-paralyzed postoperative morbidly obese patients. Chest. 1996;109:144-51.

53. Bluth T, Pelosi P, de Abreu MG. The obese patient undergoing nonbariatric surgery. Curr Opin Anaesthesiol. 2016;29:421-9.

54. Pelosi P, Luecke T, Rocco PR. Chest wall mechanics and abdominal pressure during general anaesthesia in normal and obese individuals and in acute lung injury. Curr Opin Crit Care. 2011;17:72-9.

55. Regli A, Mahendran R, Fysh ET, et al. Matching positive end-expiratory pressure to intra-abdominal pressure improves oxygenation in a porcine sick lung model of intra-abdominal hypertension. Crit Care. 2012;16:R208.

56. Kirkpatrick AW, Pelosi P, De Waele JJ, et al. Clinical review: intra-abdominal hypertension: does it influence the physiology of prone ventilation. Crit Care. 2010;14:232.

57. Mergoni M, Martelli A, Volpi A, Primavera S, Zuccoli P, Rossi A. Impact of positive end-expiratory pressure on chest wall and lung pressurevolume curve in acute respiratory failure. Am J Respir Crit Care Med. 1997; 156:846-54.

58. Verbrugge $F H$, Dupont $M$, Steels $P$, et al. Abdominal contributions to cardiorenal dysfunction in congestive heart failure. J Am Coll Cardiol. 2013;62:485-95.

59. Cheatham ML, Malbrain ML, Kirkpatrick A, et al. Results from the international conference of experts on intra-abdominal hypertension and abdominal compartment syndrome. II. Recommendations. Intensive Care Med. 2007;33:951-62.

60. De Keulenaer BL, Regli A, Malbrain ML. Intra-abdominal measurement techniques: is there anything new? Am Surg. 2011;77(Suppl 1):S17-22.

61. Mietto C, Malbrain ML, Chiumello D. Transpulmonary pressure monitoring during mechanical ventilation: a bench-to-bedside review. Anaesthesiol Intensive Ther. 2015:47(Spec No):s27-37.

62. Silva PL, Pelosi P, Rocco PR. Recruitment maneuvers for acute respiratory distress syndrome: the panorama in 2016. Rev Bras Ter Intensiv. 2016;28:104-6

63. Santiago VR, Rzezinski AF, Nardelli LM, et al. Recruitment maneuver in experimental acute lung injury: the role of alveolar collapse and edema. Crit Care Med. 2010;38:2207-14.

64. Silva PL, Cruz FF, Fujisaki LC, et al. Hypervolemia induces and potentiates lung damage after recruitment maneuver in a model of sepsisinduced acute lung injury. Crit Care. 2010;14:R114.

65. ART-Investigators, Cavalcanti AB, Suzumura ÉA, et al. Effect of lung recruitment and titrated positive end-expiratory pressure (PEEP) vs low PEEP on mortality in patients with acute respiratory distress syndrome: a randomized clinical trial. JAMA. 2017;318:1335-45.

66. Hodgson $\mathrm{CL}$, Tuxen DV, Davies AR, et al. A randomised controlled trial of an open lung strategy with staircase recruitment, titrated PEEP and targeted low airway pressures in patients with acute respiratory distress syndrome. Crit Care. 2011;15:R133.

67. Santos RS, Moraes L, Samary CS, et al. Fast versus slow recruitment maneuver at different degrees of acute lung inflammation induced by experimental sepsis. Anesth Analg. 2016;122:1089-100.

68. Rzezinski AF, Oliveira GP, Santiago VR, et al. Prolonged recruitment manoeuvre improves lung function with less ultrastructural damage in experimental mild acute lung injury. Respir Physiol Neurobiol. 2009;169:271-81.

69. Silva PL, Moraes L, Santos RS, et al. Impact of pressure profile and duration of recruitment maneuvers on morphofunctional and biochemical variables in experimental lung injury. Crit Care Med. 2011;39:1074-81.

70. Silva PL, Moraes L, Santos RS, et al. Recruitment maneuvers modulate epithelial and endothelial cell response according to acute lung injury etiology. Crit Care Med. 2013;41:e256-65.

71. Hodgson CL, Tuxen DV, Bailey MJ, et al. A positive response to a recruitment maneuver with PEEP titration in patients with ARDS, regardless of transient oxygen desaturation during the maneuver. J Intensive Care Med. 2011;26:41-9.

72. Bluth $T$, Teichmann $R$, Kiss $T$, et al. Protective intraoperative ventilation with higher versus lower levels of positive end-expiratory pressure in obese patients (PROBESE): study protocol for a randomized controlled trial. Trials. 2017;18:202 
73. Maia LA, Silva PL, Pelosi P, Rocco PRM. Controlled invasive mechanical ventilation strategies in obese patients undergoing surgery. Expert Rev Respir Med. 2017;11:443-52.

74. Moran JL, Bersten AD, Solomon PJ. Meta-analysis of controlled trials of ventilator therapy in acute lung injury and acute respiratory distress syndrome: an alternative perspective. Intensive Care Med. 2005:31:227-35.

75. PROVE NIFTCTNOTESOA, Hemmes SN, Gama de Abreu M, Pelosi P, Schultz MJ. High versus low positive end-expiratory pressure during general anaesthesia for open abdominal surgery (PROVHILO trial): a multicentre randomised controlled trial. Lancet. 2014;384:495-503.

76. Serpa Neto A, Hemmes SN, Barbas CS, et al. Protective versus conventional ventilation for surgery: a systematic review and individual patient data meta-analysis. Anesthesiology. 2015;123:66-78.

77. Lachmann B. Open up the lung and keep the lung open. Intensive Care Med. 1992;18:319-21.

78. Rhodes A, Evans LE, Alhazzani W, et al. Surviving sepsis campaign: international guidelines for management of sepsis and septic shock: 2016. Intensive Care Med. 2017;43:304-77.

79. Gattinoni L, Protti A, Caironi P, Carlesso E. Ventilator-induced lung injury: the anatomical and physiological framework. Crit Care Med. 2010;38:S539-48.

80. Talmor D, Sarge T, O'Donnell CR, et al. Esophageal and transpulmonary pressures in acute respiratory failure. Crit Care Med. 2006:34:1389-94.

81. Milic-Emili J, Mead J, Turner JM, Glauser EM. Improved technique for estimating pleural pressure from esophageal balloons. J Appl Physiol. 1964;19:207-11.

82. Malbrain ML, Cheatham ML, Kirkpatrick A, et al. Results from the international conference of experts on intra-abdominal hypertension and abdominal compartment syndrome. I. Definitions. Intensive Care Med. 2006:32:1722-32

83. Amato MB, Meade MO, Slutsky AS, et al. Driving pressure and survival in the acute respiratory distress syndrome. N Engl J Med. 2015;372:747-55.

84. Bellani G, Laffey JG, Pham T, et al. Epidemiology, patterns of care, and mortality for patients with acute respiratory distress syndrome in intensive care units in 50 countries. JAMA. 2016:315:788-800

85. De Jong A, Cossic J, Verzilli D, et al. Impact of the driving pressure on mortality in obese and non-obese ARDS patients: a retrospective study of 362 cases. Intensive Care Med. 2018;44:1106-14.

86. Nestler C, Simon P, Petroff D, et al. Individualized positive end-expiratory pressure in obese patients during general anaesthesia: a randomized controlled clinical trial using electrical impedance tomography. $\mathrm{Br} J$ Anaesth. 2017;119:1194-205.

87. Pereira SM, Tucci MR, Morais CCA, et al. Individual positive endexpiratory pressure settings optimize intraoperative mechanical ventilation and reduce postoperative atelectasis. Anesthesiology. 2018;129:1070-81.

88. Fumagalli J, Berra L, Zhang C, et al. Transpulmonary pressure describes lung morphology during decremental positive end-expiratory pressure trials in obesity. Crit Care Med. 2017;45:1374-81.

89. Fumagalli J, Santiago RRS, Teggia Droghi M, et al. Lung recruitment in obese patients with acute respiratory distress syndrome. Anesthesiology. 2019. https://doi.org/10.1097/ALN.0000000000002638.

90. Neto AS, Hemmes SN, Barbas CS, et al. Association between driving pressure and development of postoperative pulmonary complications in patients undergoing mechanical ventilation for general anaesthesia: a meta-analysis of individual patient data. Lancet Respir Med. 2016:4:272-80.

91. Malbrain ML. The saga continues: how to set best PEEP in intra-abdominal hypertension [editorial]. J Crit Care. 2018;43:387-9.

92. Pelosi P, Vargas M. Mechanical ventilation and intra-abdominal hypertension: 'Beyond Good and Evil'. Crit Care. 2012;16:187.

93. da Silva Almeida JR, Machado FS, Schettino GP, Park M, Azevedo LC. Cardiopulmonary effects of matching positive end-expiratory pressure to abdominal pressure in concomitant abdominal hypertension and acute lung injury. J Trauma. 2010;69:375-83.

94. Krebs J, Pelosi P, Tsagogiorgas C, Alb M, Luecke T. Effects of positive end-expiratory pressure on respiratory function and hemodynamics in patients with acute respiratory failure with and without intra-abdominal hypertension: a pilot study. Crit Care. 2009;13:R160.
95. Krebs J, Pelosi P, Rocco PRM, Hagmann M, Luecke T. Positive endexpiratory pressure titrated according to respiratory system mechanics or to ARDSNetwork table did not guarantee positive end-expiratory transpulmonary pressure in acute respiratory distress syndrome. J Crit Care. 2018;48:433-42.

96. Fish E, Novack V, Banner-Goodspeed VM, Sarge T, Loring S, Talmor D. The Esophageal Pressure-Guided Ventilation 2 (EPVent2) trial protocol: a multicentre, randomised clinical trial of mechanical ventilation guided by transpulmonary pressure. BMJ Open. 2014:4:e006356.

97. Regli A, De Keulenaer BL, Palermo A, van Heerden PV. Positive endexpiratory pressure adjusted for intra-abdominal pressure-a pilot study. J Crit Care. 2018;43:390-4.

98. Verzilli D, Constantin JM, Sebbane M, et al. Positive end-expiratory pressure affects the value of intra-abdominal pressure in acute lung injury/ acute respiratory distress syndrome patients: a pilot study. Crit Care. 2010;14:R137.

99. Esteban A, Frutos-Vivar F, Muriel A, et al. Evolution of mortality over time in patients receiving mechanical ventilation. Am J Respir Crit Care Med. 2013;188:220-30.

100. Saddy F, Sutherasan Y, Rocco PR, Pelosi P. Ventilator-associated lung injury during assisted mechanical ventilation. Semin Respir Crit Care Med. 2014;35:409-17.

101. Magalhães PAF, Padilha GA, Moraes L, et al. Effects of pressure support ventilation on ventilator-induced lung injury in mild acute respiratory distress syndrome depend on level of positive end-expiratory pressure: a randomised animal study. Eur J Anaesthesiol. 2018;35:298-306.

102. Güldner A, Kiss T, Serpa Neto A, et al. Intraoperative protective mechanical ventilation for prevention of postoperative pulmonary complications: a comprehensive review of the role of tidal volume, positive end-expiratory pressure, and lung recruitment maneuvers. Anesthesiology. 2015;123:692-713.

103. Carvalho NC, Güldner A, Beda A, et al. Higher levels of spontaneous breathing reduce lung injury in experimental moderate acute respiratory distress syndrome. Crit Care Med. 2014;42:e702-15.

104. Saddy F, Oliveira GP, Garcia CS, et al. Assisted ventilation modes reduce the expression of lung inflammatory and fibrogenic mediators in a model of mild acute lung injury. Intensive Care Med. 2010;36:1417-26.

105. Santos CL, Santos RS, Moraes L, et al. Effects of pressure support and pressure-controlled ventilation on lung damage in a model of mild extrapulmonary acute lung injury with intra-abdominal hypertension. PLOS ONE. 2017;12:e0178207.

106. Henzler D, Hochhausen N, Bensberg R, et al. Effects of preserved spontaneous breathing activity during mechanical ventilation in experimental intra-abdominal hypertension. Intensive Care Med. 2010;36:1427-35.

107. Sud S, Friedrich JO, Taccone $P$, et al. Prone ventilation reduces mortality in patients with acute respiratory failure and severe hypoxemia: systematic review and meta-analysis. Intensive Care Med. 2010;36:585-99.

108. Guérin C, Reignier J, Richard JC, et al. Prone positioning in severe acute respiratory distress syndrome. N Engl J Med. 2013;368:2159-68.

109. Mure M, Glenny RW, Domino KB, Hlastala MP. Pulmonary gas exchange improves in the prone position with abdominal distension. Am J Respir Crit Care Med. 1998;157:1785-90.

110. Keenan JC, Cortes-Puentes GA, Zhang L, Adams AB, Dries DJ, Marini J. PEEP titration: the effect of prone position and abdominal pressure in an ARDS model. Intensive Care Med Exp. 2018:6:3.

111. De Jong A, Molinari N, Sebbane M, et al. Feasibility and effectiveness of prone position in morbidly obese patients with ARDS: a case-control clinical study. Chest. 2013;143:1554-61.

112. Jozwiak M, Teboul JL, Anguel N, et al. Beneficial hemodynamic effects of prone positioning in patients with acute respiratory distress syndrome. Am J Respir Crit Care Med. 2013;188:1428-33.

113. Ball CG, Kirkpatrick AW, Pelosi P, De Waele J. Intra-abdominal hypertension, prone ventilation, and abdominal suspension. J Trauma. 2010;68:1017.

114. Kirkpatrick AW, Keaney M, Hemmelgarn B, et al. Intra-abdominal pressure effects on porcine thoracic compliance in weightlessness: implications for physiologic tolerance of laparoscopic surgery in space. Crit Care Med. 2009;37:591-7.

115. Malbrain ML, De Waele JJ, De Keulenaer BL. What every ICU clinician needs to know about the cardiovascular effects caused by abdominal hypertension. Anaesthesiol Intensive Ther. 2015;47:388-99. 
116. Mahjoub Y, Plantefeve G. Cardiac ultrasound and abdominal compartment syndrome. Acta Clin Belg. 2007;62(Suppl):183-9.

117. Soni N, Williams P. Positive pressure ventilation: what is the real cost? Br J Anaesth. 2008;101:446-57.

118. Cheatham ML, Malbrain ML. Cardiovascular implications of abdominal compartment syndrome. Acta Clin Belg. 2007;62(Suppl):98-112.

119. Kitano Y, Takata M, Sasaki N, Zhang Q, Yamamoto S, Miyasaka K. Influence of increased abdominal pressure on steady-state cardiac performance. J Appl Physiol. 1999:86:1651-6.

120. Fellahi JL, Caille V, Charron C, Daccache G, Vieillard-Baron A. Hemodynamic effects of positive end-expiratory pressure during abdominal hyperpression: a preliminary study in healthy volunteers. J Crit Care. 2012;27:33-6.

121. De Keulenaer B, Regli A, De Laet I, Roberts D, Malbrain ML. What's new in medical management strategies for raised intra-abdominal pressure: evacuating intra-abdominal contents, improving abdominal wall compliance, pharmacotherapy, and continuous negative extra-abdominal pressure. Anaesthesiol Intensive Ther. 2015;47:54-62.
122. Regli A, De Keulenaer B, De Laet I, Roberts D, Dabrowski W, Malbrain ML. Fluid therapy and perfusional considerations during resuscitation in critically ill patients with intra-abdominal hypertension. Anaesthesiol Intensive Ther. 2015;47:45-53.

123. Fan E, Del Sorbo L, Goligher EC, et al. An official American Thoracic Society/European Society of Intensive Care Medicine/Society of Critical Care Medicine clinical practice guideline: mechanical ventilation in adult patients with acute respiratory distress syndrome. Am J Respir Crit Care Med. 2017:195:1253-63.

124. ARDS-Network, Brower RG, Matthay MA, et al. Ventilation with lower tidal volumes as compared with traditional tidal volumes for acute lung injury and the acute respiratory distress syndrome. N Engl J Med. 2000;342:1301-8.

125. Papazian L, Forel JM, Gacouin A, et al. Neuromuscular blockers in early acute respiratory distress syndrome. N Engl J Med. 2010;363:1107-16.

126. Malbrain ML, De Laet IE. Intra-abdominal hypertension: evolving concepts. Clin Chest Med. 2009;30(1):45-70.

\section{Submit your manuscript to a SpringerOpen ${ }^{\circ}$ journal and benefit from:}

- Convenient online submission

- Rigorous peer review

- Open access: articles freely available online

- High visibility within the field

Retaining the copyright to your article

Submit your next manuscript at $\boldsymbol{\nabla}$ springeropen.com 